\title{
Study of Habitat's Thermal Performance Equipped with an Adsorption Cooling Unit by Geothermal Heat Pump
}

\author{
Djanfar El-Maktoume1,2*, Xavier Chesneau', Abdoulaye Diallo ${ }^{1,3}$, \\ Zely Arivelo Randriamanantany²
}

${ }^{1}$ Laboratoire de Modélisation Pluridisciplinaire et Simulations (LAMPS), Université de Perpignan Via DOMITIA, Perpignan, France ${ }^{2}$ Laboratoire de Thermodynamique, Thermique et Combustion (LTTC) de l'Equipe d'Accueil Doctorale Physique du Globe, de l'Énergie et de l'Environnement (PGEE), Université d'Antananarivo, Antananarivo, Madagascar ${ }^{3}$ Laboratoire d'Enseignement et de Recherche en Energétique Appliquée (LEREA), Université Gamal Abdel Nasser de Conakry, Conakry, Guinée

Email: *maktoumdjanfar@yahoo.fr

How to cite this paper: El-Maktoume, D., Chesneau, X., Diallo, A. and Randriamanantany, Z.A. (2021) Study of Habitat's Thermal Performance Equipped with an Adsorption Cooling Unit by Geothermal Heat Pump. Journal of Power and Energy Engineering, 9, 26-52.

https://doi.org/10.4236/jpee.2021.98003

Received: June 29, 2021

Accepted: August 16, 2021

Published: August 19, 2021

Copyright (c) 2021 by author(s) and Scientific Research Publishing Inc. This work is licensed under the Creative Commons Attribution International License (CC BY 4.0).

http://creativecommons.org/licenses/by/4.0/

\begin{abstract}
This work concerns a modeling of habitat equipped with an adsorption cooling unit powered by a geothermal heat pump in the context of the climate of the Comoros Islands. Cooling unit is a simple system consisting of an adsorber, condenser and evaporator. The modeling of the habitat-air conditioning system was based on a description of heat and mass transfers. The first law of thermodynamics on the energy conservation using the analogies between heat and electrical transfers is used to establish the equations of the model. Zeolite-methanol pair and Dubinin-Astakhov adsorption model are used to describe the amount of adsorbed mass. The finite difference method applied to a point of the considered exchange surface is used to discretize equations and resolve them. The coupling of the system takes place through a convective transfer between the air inside habitat and the evaporator's surface. This article presents results for typical November days in Comoros. Different temperatures of habitat with and without a cooling unit show that using the adsorption cooling unit can help lower internal temperatures. We observe a temperature difference of $2.14 \mathrm{~K}$ in particular at 2 p.m., if the air conditioning starts at 8 a.m. The influence of the input parameters on the air inside the habitat makes it possible to assess the impact on indoor comfort. The $\mathrm{COP}_{\text {th }}$ can reach 0.46 . However, we can get a high performance if we optimize temperature thresholds. These show that this type of cooling unit can help improve the habitat thermal comfort in a tropical and dry climate.
\end{abstract}




\section{Keywords}

Cooling, Habitat, Adsorption, Geothermal, Optimization

\section{Introduction}

The part of energy used in the world for air conditioning continues to grow. In 2100 , such an amount of energy is estimated to increase by $72 \%$ due to the development of modern architectures, the improvement of socioeconomic living conditions and the affordable price of air conditioning systems [1] [2]. The development of passive air conditioning systems, the improvement of the energy efficiency of the building's envelope or the use of renewable energies can help reduce this energy. Therefore, the promotion of new air conditioning techniques with low energy consumption is essential. Passive air conditioning is among those promising techniques, [3]. It consists in minimizing the action of external conditions on the internal environment by various techniques and in exploiting the architectural characteristics of buildings. These techniques are mainly based on the design of modern and sometimes bioclimatic habitat models in which materials or devices capable of cooling them are used in an efficient and clean manner and with low maintenance and production costs. Adsorption cooling systems are one such design. They are thermodynamic devices capable of transforming an energy source to produce cooling effects. Overall, many studies on these systems focus on improving heat and mass transfer in the adsorber proving that the intensification of heat and mass transfer properties on the bed adsorber can be effectively obtained by preparing thin thickness adsorber bed [4] and using new [5] or highly conductive materials [6] such as carbon fibers [7] as well as consolidated composite adsorbents [8] [9]. The technique for preparing consolidated composite adsorbents consists of adding material with greater thermal conductivity [10] to the powder of the classic solid adsorbent. These techniques make it possible to design cooling units with improved power densities, [11] [12]. Other recent studies show that the use of directed mass transfer channels [13] [14] or structures with metal organics [15] [16] [17] in the adsorber bed make it possible to capitalize the heat and mass transfers. Other authors study the thermodynamic cycles of the different adsorption couples of a solar cooling machine, [18] [19]. Some of them find that the cycle discontinuity problem can be solved by using several adsorber beds [20] despite the increased size, weight, and price of the machine. Using two adsorbers gives the possibility to demonstrate transfer of energy from one adsorber to another when the average temperature of one is lower than the other and the temperature of output of one is higher than the other, [21]. This solution is particularly effective in removing the intermittent factor from the adsorption heat pump. Further, much effort has been devoted to developing heat pumps with advanced adsorption cycles (dispersant mat, thermal waves, reduction of regeneration heat, etc.), [22]. In addition, other scholars analyze the in- 
fluence of system parameters to improve the cycle of the adsorption heat pump, [23]. They do so by examining the impacts of different system characteristics on cycle performance including threshold temperatures, cycle times, the location of valves at the inlet and outlet of the adsorber bed. Therefore, the prospect of using these technologies in tropical countries with high potential in renewable resources is remarkably interesting, both for air conditioning of course but also for ice production. This is also the interest of the studies several authors carried out [24] [25] using photovoltaic solar energy. In this article, we are interested in using these technologies while valuing geothermal energy, an energy resource that Comoros views as having a high potential thanks to the presence of a rift associated with the active volcano Karthala, [26]. The country has a vast geothermal reserve still unexploited to this day. This utilization attracts more and more experts in the energy sector along with those working in the fields of economic and social development. The study of the geological structures, the observed surface thermal releases as well as the geophysical observations all indicate the presence of an active hydrothermal system in this Country, [27] [28] [29]. This work aims at evaluating the thermal performance of a habitat that is equipped with an adsorption cooling unit powered by geothermal heat for a dry and humid tropical climate. Thus, we propose a mathematical model which describes the operation of an air conditioning system of a habitat composed of a geothermal heat pump coupled to a cooling production unit by adsorption, a system also coupled with a model of habitat. The modeling of the system concerns, on the one hand, the heat and mass transfers of the cooling unit by adsorption supplied by a geothermal source and, on the other hand, the heat transfers in a single-zone habitat exposed to local climatic conditions. We operate/deploy the cooling of the internal air of the habitat by making a coupling between the surface of the evaporator and the air inside the habitat. Then, over time, we observe the evolution of the various parameters of the system, including the internal temperatures of the home with and without the cooling unit. Finally, we present the influence of the various input parameters of the system in order to see their impacts on the thermal comfort of the habitat, in the context of the climate of the Comoro Islands.

\section{Materials and Methods}

\subsection{Climate}

The climate of the Comoros Islands is tropical, dry, humid and divided into two main seasons. The two seasons: the "kusi" and the "kashkazi" dominate the climate of the country throughout the year and determine the climatic regime of the archipelago. Although, there is little variation of temperature during the year, the country still experiences quite high temperatures between the two seasons, which vary from around 296 to $308 \mathrm{~K}$ with an average of $301 \mathrm{~K}$. The country's habitats are exposed to these climatic conditions. Very often, the latter causes the strong increase of the temperature of the air indoor. This situation is sometimes difficult to live with and is far from providing thermal comfort to the oc- 
cupants.

\subsection{Physical Description of the System}

The model refers to a "typical" habitat in Comoros equipped with an adsorption cooling unit. This condition involves an infrastructure with them in front facade oriented towards the west. This is a mono-zone habitat consisting of a roof and a habitable enclosure. A plastic ceiling is used between the roof and the living area. This ceiling allows the separation of the confined air inside the roof and the living space. The habitat has a floor area of $12 \mathrm{~m}^{2}$ for a $3 \mathrm{~m}$ wall height. Different parts of the habitat are decomposed as follows:

- A roofing, triangular shape whose height is equal to $0.9 \mathrm{~m}$, is assimilated to a type plan captor inclined relative to the horizontal on each of the north and south sides. It is composed of a sheet metal roof, absorption coefficient equal to 0.8 , and stabilized thanks to iron beams. The east and west sides of the roof are the extensions of the respective walls east and west of the living space;

- A living space has a parallelepiped shape. It is composed of a chamber whose vertical walls, absorption coefficient equal to 0.4 , are built by cement bricks with fine sand. The walls, thickness equal to $15 \mathrm{~cm}$, are stabilized by cement posts, sand, stone and iron. The floor is made of a concrete form of rectangular plate. All the materials used are available in the local market. We used the habitat measures of the National Planning Plan. Table 1 summarizes the thermal physical properties of the materials.

The cooling unit is an adsorption heat pump consisting of an adsorber captor, an air condenser and an evaporator placed on one of the internal faces of the habitat walls. The adsorber captor is cylindrical in shape and horizontally laid. It is composed of an external thick wall and an inner small wall (partition) inside which the geothermal fluid circulates. It is connected, on the one hand, by vapor tubes with the condenser and the evaporator, and on the other hand, by the pipe where the geothermal fluid circulates. The zeolite layer, loaded in methanol, is deposited between the wall and the partition so that it occupies the entire volume available. The air condenser is double wall parallelepiped in shape allowing the condensation of the adsorbate vapor at high pressure. It is in constant contact with the ambient environment. The condenser is used so that the liquid condensate is easily removed under the effect of gravity. The ambient temperature at

Table 1. Thermal physical properties of the materials [3].

\begin{tabular}{cccc}
\hline Component & Thermal conductivity $(\mathrm{W} / \mathrm{m} \cdot \mathrm{K})$ & Specific heat $(\mathrm{J} / \mathrm{kg} \cdot \mathrm{K})$ & Density $\left(\mathrm{kg} / \mathrm{m}^{3}\right)$ \\
\hline Sheet metal & 0.752 & 800 & 1200 \\
Roof & 0.24 & 2300 & 650 \\
Wall & 1.1 & 900 & 1500 \\
Floor & 0.9 & 840 & 2300 \\
\hline
\end{tabular}


night and cold circulation during the day are supposed to cool the condenser. The evaporator, sample, in which the condensate evaporates at evaporation pressure.

\subsection{Working Principle}

The habitat's thermal operation is driven by the solar flow action and the temperature levels outside. The incident solar flux arrives on the habitat's roof and walls. The sheets and walls absorb a part of it and the conduction transmits the rest to the inner air. This heat enters the living room in the ceiling and the walls. The inner temperature of the habitat increases under the conjugate effect of the solar flux and the exterior ambient temperature. Heat transfers occur mainly by conduction, convection and radiation. The exchange by renewal takes place at the level of the main openings. We illustrate all of these thermal exchanges in Figure 1. As for the cooling unit (Figure 2), its operation is provided by zeolite and methanol. The base cycle of the cooling unit is closed and intermittent. It breaks down into two phases during the first phase, the fluid receives the geothermal heat with high temperature and releases it during the condensation of methanol in the condenser at intermediate temperature. This is the regeneration-condensation phase. During the second phase, the methanol is vaporized in the evaporator by taking heat from the low temperature source and is fixed to the intermediate temperature zeolite. This is the adsorption-evaporation phase. We define the thermodynamic cycle by the different operating temperatures of

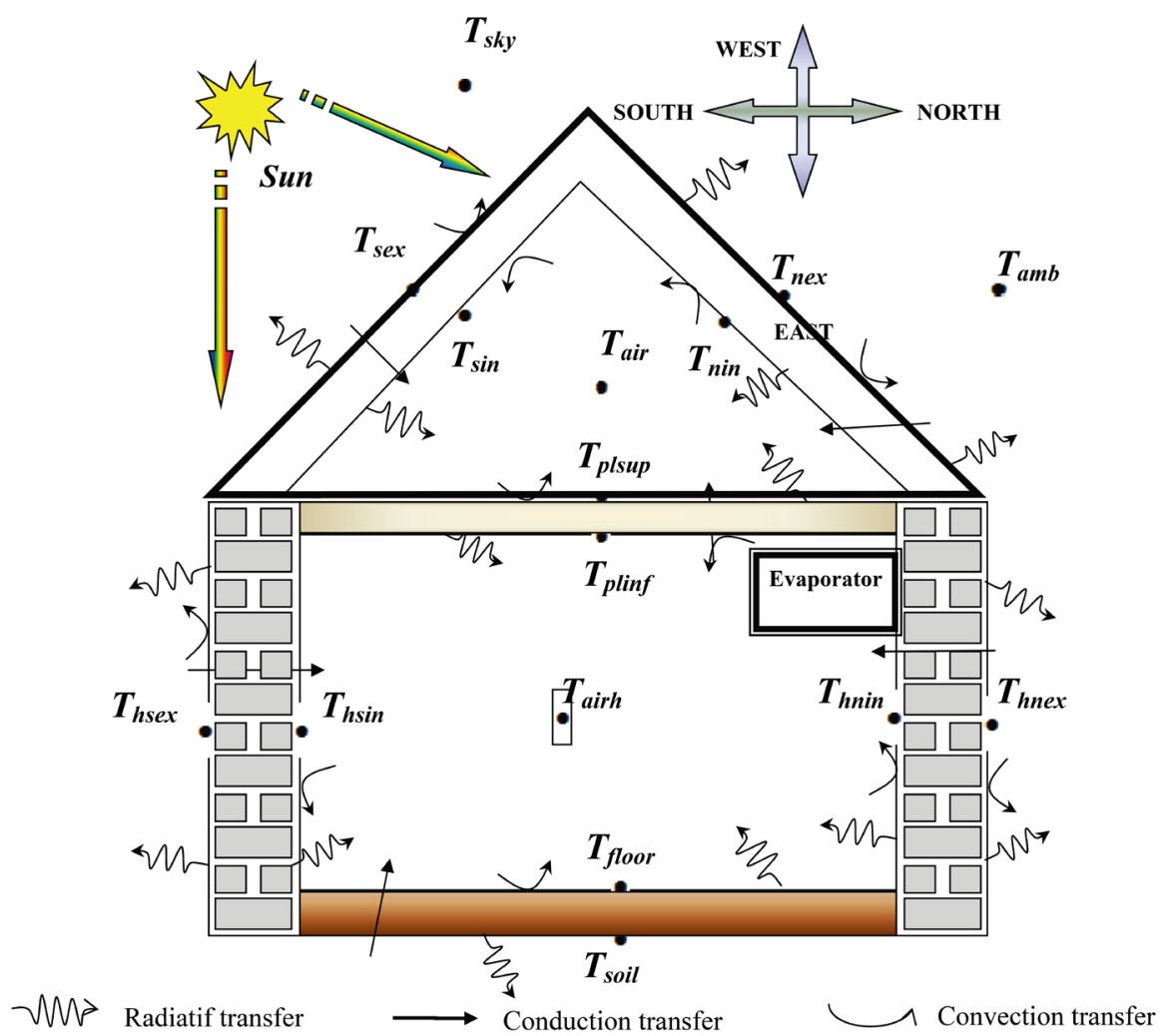

Figure 1. Thermal exchange in habitat. 


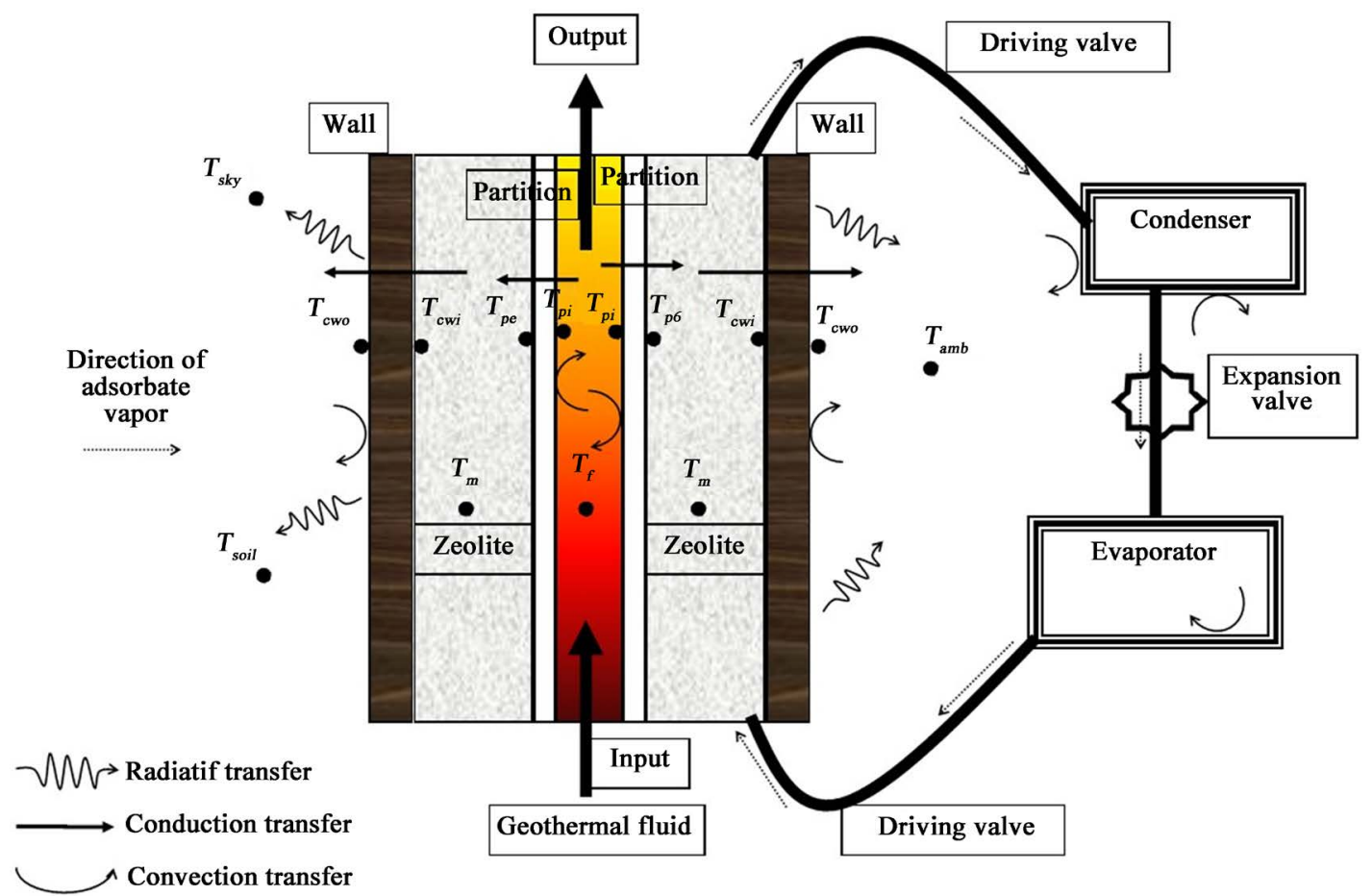

Figure 2. Thermal exchange in the adsorption cooling unit.

the system: evaporation temperature $T_{\text {eva }}$ condensation temperature $T_{\text {cond }}$ adsorption temperature $T_{\text {ads }}$ and regeneration temperature $T_{g}$.

For the system to work, we inject the geothermal fluid inside the adsorber with a constant flow rate to heat the metal parts of the adsorber. In contact with the walls, it transmits its heat that propagates by convection related to the flow imposed at the inlet. This heat is then transmitted by conduction to the zeolite/methanol mixture. The increasing of the zeolite's temperature creates the desorption of methanol vapor The methanol vapor is redirected to the condenser and after crossing a throttle valve, the liquid refrigerant passes to the evaporator in which it evaporates at the evaporation pressure, thus taking heat from the evaporator.

\subsection{Mathematical Formulation}

\subsubsection{Assumptions}

We make the following assumptions:

- Thermal transfers are unidirectional;

- Physical properties of materials are constant;

- Adsorber captor is cylindrical symmetrical;

- Pressure is constant in the condenser and evaporator;

- Entire adsorbate mass adsorbed is condensed;

- In the captor, zeolite and methanol are similar to a homogeneous medium.

\subsubsection{Equations Model}

To establish the equations governing the model, we use a methodology based on 
the nodal approach. The system is assimilated to a thermal system where each element is considered as an integral component of the system. Thus, each element corresponds to a single temperature. We establish the equations of the thermal balance based on the analogy between the thermal and electrical transfers. To formulate the problem mathematically, we consider any node $i$ of an element of the system to which we apply energy conservation. We suggest writing the general heat balance equation using the following form:

$$
M_{i} \cdot C p_{i}\left(\frac{\partial T_{i}}{\partial t}\right)=\sum_{i} h_{i j}^{x} \cdot S_{i} \cdot(\Delta T)_{i, j}+\left(\alpha_{i} \varphi_{i}\right)
$$

\subsubsection{Balance of Heat and Mass Transfers of System}

The balance of heat and mass transfers of cooling unit can be written as follow:

- For the geothermal fluid,

$$
M_{f} \cdot C p_{f}\left(\frac{\partial T_{f}}{\partial t}+U \frac{T_{f}-T_{f-1}}{\Delta x}\right)=S_{p i} h_{f, p i}^{c v}\left(T_{p i}-T_{f}\right)
$$

- For the inner small wall,

$$
\frac{M_{p} \cdot C p_{p}}{S_{p}}\left(\frac{\partial T_{p i}}{\partial t}\right)=h_{f, p i}^{c v} \cdot\left(T_{f}-T_{p i}\right)+\frac{\lambda_{p}}{e p_{p}}\left(T_{p o}-T_{p i}\right)
$$

- For the outer small wall,

$$
\frac{M_{p} \cdot C p_{p}}{S_{p}}\left(\frac{\partial T_{p o}}{\partial t}\right)=\frac{\lambda_{p}}{e p_{p}}\left(T_{p i}-T_{p o}\right)+\frac{2 \lambda_{z}}{e p_{z}}\left(T_{m}-T_{p o}\right)
$$

- For the mixture zeolite/methanol,

When heating-desorption [24],

$$
\begin{aligned}
& \left(M_{z} C p_{z}+m \cdot M_{z} C p_{e}\right)\left(\frac{\partial T_{m}}{\partial t}\right) \\
& =\delta\left[\Delta H_{\text {des }} M_{z} \frac{\partial m_{e}^{d e s}}{\partial t}+M_{z} C p_{e}\left(T_{m}-T_{c d}\right) \frac{\partial m_{e}^{d e s}}{\partial t}\right] \\
& +S_{p} \frac{2 \lambda_{z}}{e p_{z}}\left(T_{p o}-T_{m}\right)+S_{c w} \frac{2 \lambda_{z}}{e p_{z}}\left(T_{c w i}-T_{m}\right)
\end{aligned}
$$

When cooling-adsorption [24],

$$
\begin{aligned}
& \left(M_{z} C p_{z}+m \cdot M_{z} C p_{e}\right)\left(\frac{\partial T_{m}}{\partial t}\right) \\
& =\delta\left[\Delta H_{a d s} M_{z} \frac{\partial m_{e}^{a d s}}{\partial t}-M_{z} C p_{e}\left(T_{m}-T_{e v}\right) \frac{\partial m_{e}^{a d s}}{\partial t}\right] \\
& +S_{p} \frac{2 \lambda_{z}}{e p_{z}}\left(T_{p o}-T_{m}\right)+S_{c w} \frac{2 \lambda_{z}}{e p_{z}}\left(T_{c w i}-T_{m}\right)
\end{aligned}
$$

where $\delta=0$ for heating and cooling and $\delta=1$, for desorption and adsorption.

- For the inner face of the cooling unit wall,

$$
\frac{M_{c w} \cdot C p_{c w}}{S_{c w}}\left(\frac{\partial T_{c w i}}{\partial t}\right)=\frac{2 \lambda_{z}}{e p_{z}}\left(T_{m}-T_{c w i}\right)+\frac{\lambda_{c w}}{e p_{c w}}\left(T_{c w o}-T_{c w i}\right)
$$


- For the outer face of the cooling unit wall,

$$
\begin{aligned}
\frac{M_{c w} \cdot C p_{c w}}{S_{c w}}\left(\frac{\partial T_{c w o}}{\partial t}\right)= & \frac{\lambda_{c w}}{e p_{c w}}\left(T_{c w i}-T_{c w o}\right)+h_{a m b}^{c v}\left(T_{a m b}-T_{c w o}\right) \\
& +h_{c w o, s k y}^{r}\left(T_{s k y}-T_{c w o}\right)+h_{c w o, s o i l}^{r}\left(T_{\text {soil }}-T_{c w o}\right)
\end{aligned}
$$

- For the condenser,

$$
\begin{aligned}
& {\left[M_{c d} C p_{c d}+m_{e}(t) C p_{e}\right] \frac{\partial T_{c d}}{\partial t}} \\
& =\left(\alpha_{c d} G_{h}\right)+S_{c d} h_{c d, a m b}^{c v}\left(T_{a m b}-T_{c d}\right)+S_{c d} h_{c d, s k y}^{r}\left(T_{s k y}-T_{c d}\right) \\
& \quad+S_{c d} h_{c d, s o i l}^{r}\left(T_{s o i l}-T_{c d}\right)+M_{z} \frac{\partial m_{e}^{d e s}}{\partial t}\left[L_{c d}\left(P_{c d}\right)+C p_{e}\left(T_{m}-T_{c d}\right)\right]
\end{aligned}
$$

- For the evaporator,

$$
\begin{aligned}
& {\left[M_{e v} C p_{e v}+\left(m_{e}(t)-\Delta m \cdot m_{z}\right) C p_{e}\right] \frac{\partial T_{e v}}{\partial t}} \\
& =S_{e v} h_{e v}^{c v}\left(T_{\text {airh }}-T_{e v}\right)-m_{z} \frac{\partial m_{e}^{a d s}}{\partial t}\left[L_{e v}\left(P_{e v}\right)-C p_{e}\left(T_{m}-T_{e v}\right)\right]
\end{aligned}
$$

The balance of heat and mass transfers for the habitat can be written as follow:

- For the external wall of the habitat,

$$
\begin{aligned}
\frac{M_{h} C p_{h}}{S_{h}}\left(\frac{\partial T_{\text {hex }}}{\partial t}\right)= & \left(\alpha_{h} I\right)+\frac{\lambda_{h}}{e p_{h}}\left(T_{\text {hin }}-T_{\text {hex }}\right)+h_{a m b}^{c v}\left(T_{\text {amb }}-T_{\text {hex }}\right) \\
& +h_{\text {hex }, \text { soil }}^{r}\left(T_{\text {soil }}-T_{\text {hex }}\right)+h_{\text {hex }, \text { sky }}^{r}\left(T_{\text {sky }}-T_{\text {hex }}\right)
\end{aligned}
$$

- For the internal wall of the habitat,

$$
\frac{M_{h} C p_{h}}{S_{h}}\left(\frac{\partial T_{\text {hin }}}{\partial t}\right)=\frac{\lambda_{h}}{e p_{h}}\left(T_{h e x}-T_{h i n}\right)+h_{\text {hin, air }}^{c v}\left(T_{\text {air }}-T_{\text {hin }}\right)+\sum h_{\text {hin }, j}^{r}\left(T_{j}-T_{\text {hin }}\right)
$$

- For the air inside the living space,

$$
M_{\text {airh }} C p_{\text {air }}\left(\frac{\partial T_{\text {airh }}}{\partial t}\right)=\sum h_{j, \text { airh }}^{c v} S_{j}\left(T_{j}-T_{\text {airh }}\right)+S_{e v} h_{e v}^{c v}\left(T_{e v}-T_{\text {airh }}\right)+\phi_{\text {air }}
$$

\subsubsection{Expression of Heat Transfer Coefficients}

The coefficient between the walls and the ambient can be written as follow [30]:

$$
h_{a m b}^{c \nu}=5.67+3.86 \times V
$$

The coefficient which reflects the convective exchanges between the geothermal fluid and the inner small wall is expressed as [31]:

$$
N_{u}=0.023 P_{r}^{\frac{1}{3}} R_{e}^{0.8}\left[1+\left(\frac{D_{m}}{L_{c}}\right)^{0.7}\right]
$$

The convective transfer coefficient between the living space air and the vertical walls in the habitat is given by the following relation [32]:

$$
N_{u}=0.68+0.67 R_{a}^{\frac{1}{4}}\left[1+\left(\frac{0.492}{P_{r}}\right)^{\frac{9}{16}}\right]^{-\frac{4}{9}} ; 10^{-5}<R_{a}<10^{12}
$$


The convective transfer coefficient between the living space air and the horizontal walls is calculated with the following expression [30]:

$$
N_{u}=0.27\left(R_{a}\right)^{1 / 4}
$$

The coefficient which reflects the transfers by radiation between two surfaces is given by the following expression [33]:

$$
h_{i, j}^{r}=\frac{\sigma \cdot\left(T_{i}^{2}+T_{j}^{2}\right)\left(T_{i}+T_{j}\right)}{\frac{1-\varepsilon_{i}}{\varepsilon_{i}}+\frac{1}{F_{i, j}}+\frac{1-\varepsilon_{j} \cdot S_{i}}{\varepsilon_{j} S_{j}}}
$$

The sky temperature is given by the expression:

$$
T_{\text {sky }}=0.0552 \times\left(T_{a m b}\right)^{1.5}
$$

The exchange rate by renewal of air is given by:

$$
\phi_{\text {air }}=c \times N \times V_{\text {ol }} \times\left(T_{\text {amb }}-T_{\text {airh }}\right)
$$

\subsubsection{Adsorption Model}

We use the Dubinin-Astakhov thermodynamic model and the general adsorption equation is given by the expression [34]:

$$
w=w_{0} \exp \left[-\left(\frac{\varepsilon}{E_{a}}\right)^{n}\right]
$$

The equation expressing the mass adsorbed $m_{e}$ is given by the following expression:

$$
m_{e}(t)=w_{0} \rho_{e}(T) \exp \left\{-\left(\frac{R}{E_{a}}\right)^{n}\left[T \ln \left(\frac{P_{s}(T)}{P}\right)\right]^{n}\right\}
$$

In addition, we use the Linear Driving Force (LDF) model to determine the flow rate of adsorbed methanol vapor. It is expressed by [35]:

$$
\frac{\partial m_{e}}{\partial t}=k\left(m_{0}-m_{e}(t)\right)
$$

\subsubsection{Thermal Coefficient of Performance}

The thermal coefficient of the performance of the air conditioner unit is given by the following expression, [36]:

$$
C O P_{t h}=\frac{Q_{e v}}{Q_{\text {total }}}
$$

The amount of cold produced at the evaporator is given by the expression:

$$
\begin{aligned}
Q_{e v} & =\Delta m \cdot m_{z}\left[L\left(T_{\text {eva }}\right)-\int_{T_{\text {eva }}}^{T_{\text {cond }}} C p_{e}(T) \mathrm{d} T\right] \\
& =\Delta m \cdot m_{z}\left[L\left(T_{\text {eva }}\right)-C p_{e}\left(T_{\text {cond }}-T_{\text {eva }}\right)\right]
\end{aligned}
$$

$\Delta m$ : this is the mass of the cycled methanol per $\mathrm{kg}$ of zeolite calculated using the difference in adsorbate mass between the two isosteric transformations by 
the equation:

$$
\Delta m=m_{\max }-m_{\min }=m\left(T_{a d s}, P_{e v}\right)-m\left(T_{g}, P_{c d}\right)
$$

\subsection{Climate Conditions}

The overall flow and ambient temperature are similar to sinusoidal functions. The climate data we use in this work are those of typical days of November in the Comoros Islands spanning over the 2009-2019 period. These days are marked by maximum average temperatures equal to $305.76 \mathrm{~K}$ and minimum equal to 298.46 $\mathrm{K}$. The maximum flux intensity is $1000 \mathrm{~W} / \mathrm{m}^{2}$. Figures 3-5 represent climate conditions for these typical days of November in Comoros.

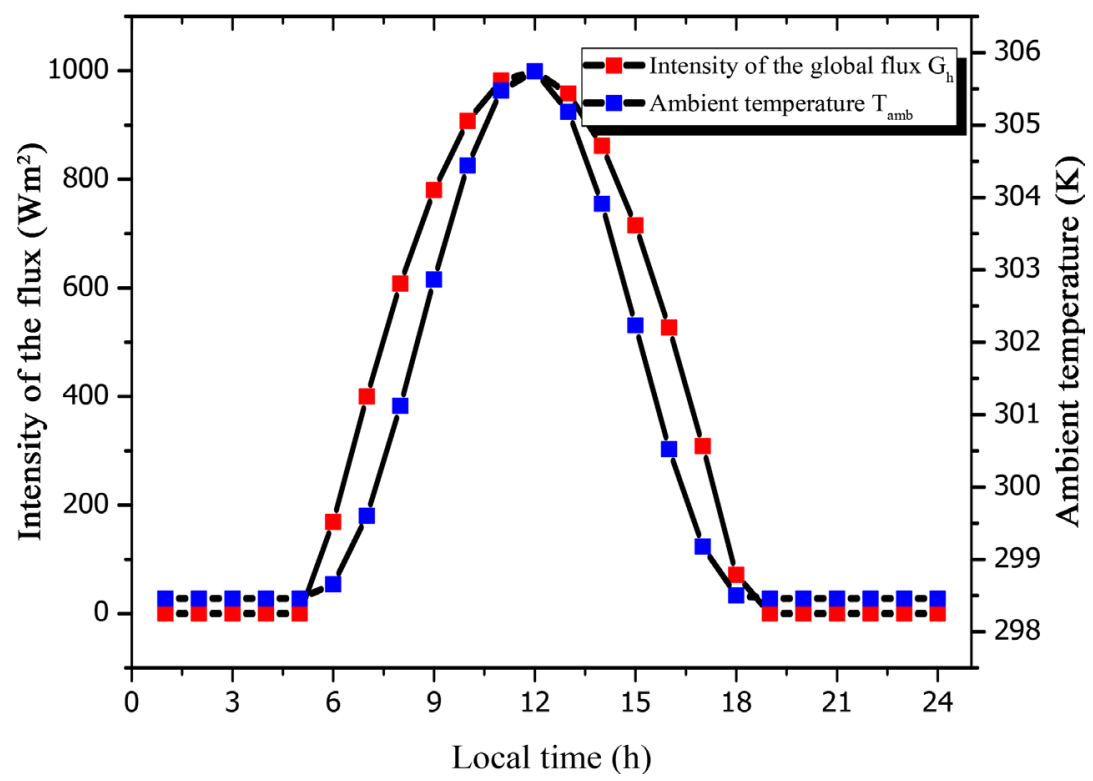

Figure 3. Evolution of ambient temperature and horizontal global flux.

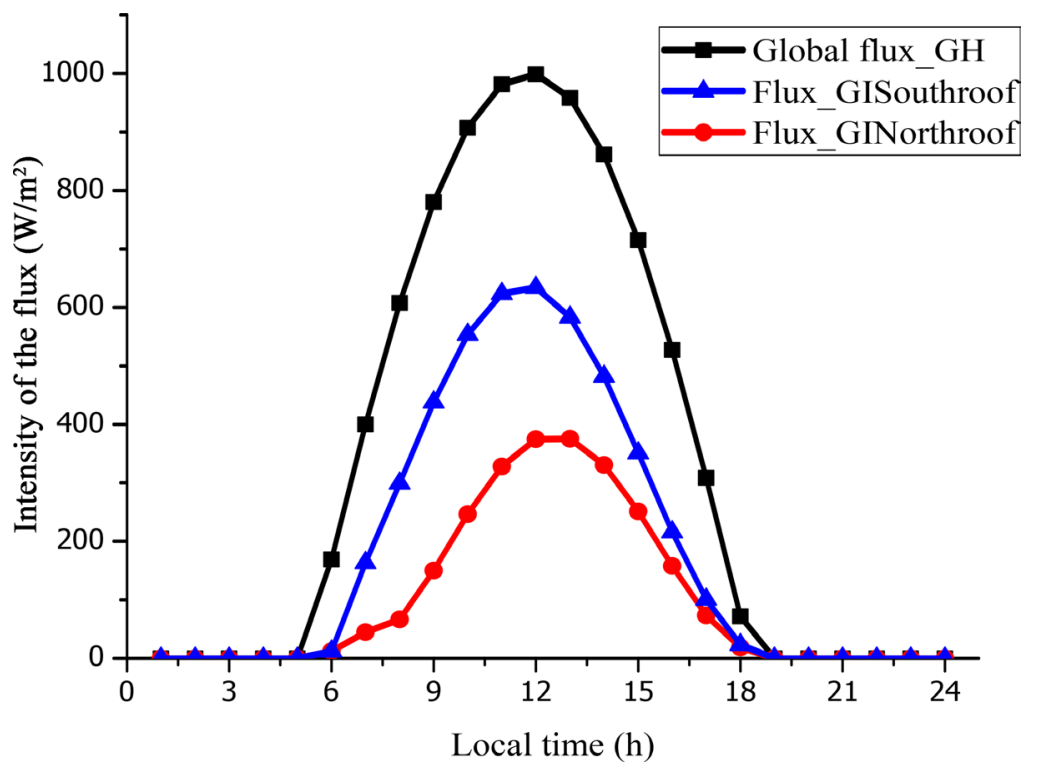

Figure 4. Evolution of incident flux on the roof. 


\subsection{Resolution Method}

We discretize the system equations with the implicit finite difference method. The resolution is made by using an iterative calculation using the Gauss algorithm. It allows us to determine in Physics involved according to the unknown variables at $t+\Delta t$ time on the one hand and the variables known at the previous $t$ on the other hand. Table 2 groups the main parameters we used during the simulation.

\section{Results and Discussions}

\subsection{Model Validation}

In order to validate our code, we compare the shape of the cycle we obtain with the data reported by A. Al Fadar and al. [36]. Figure 6 shows the evolution of the cycle of this study and the one A. Al Fadar and al. obtained in their study of a refrigeration system by adsorption powered by a solar parabolic captor.

They studied the activated carbon/ammonia. By comparing the two cycles, we find gaps, in particular at the end of the cooling/heating and at the beginning of adsorption-evaporation. These differences can be explained by the different

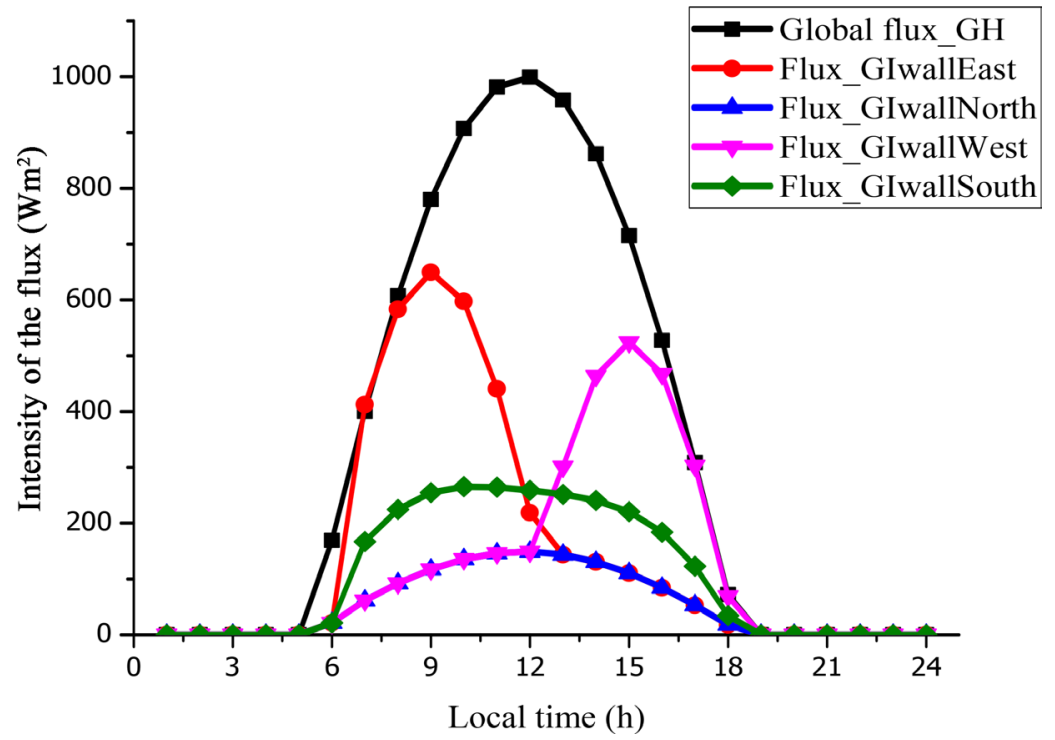

Figure 5. Evolution of incident flux on the habitat's walls.

Table 2. Main parameters used for simulation.

\begin{tabular}{cccc}
\hline$C p_{z}$ & $836 \mathrm{~J} / \mathrm{Kg} / \mathrm{K}$ & $C p_{p}$ & $1800 \mathrm{~J} / \mathrm{Kg} / \mathrm{K}$ \\
$\rho_{z}$ & $980 \mathrm{~kg} / \mathrm{m}^{3}$ & $\rho_{p}$ & $1200 \mathrm{~kg} / \mathrm{m}^{3}$ \\
$C p_{c w}$ & $1278 \mathrm{~J} / \mathrm{Kg} / \mathrm{K}$ & $\lambda_{p}$ & $200.758 \mathrm{~W} \cdot \mathrm{m}^{-1} \cdot \mathrm{K}^{-1}$ \\
$\rho_{c w}$ & $1300 \mathrm{~kg} / \mathrm{m}^{3}$ & $w_{o}$ & 0.269 \\
$T_{f}$ & $363 \mathrm{~K}$ & $E_{a}$ & $8134 \times 10^{4} \mathrm{~J}$ \\
$P_{\text {ev }}=P_{s}\left(T_{\text {eva }}\right)$ & $6129 \mathrm{~Pa}$ & $D$ & $415 \times 10^{-7}$ \\
$P_{c d}=P_{s}\left(T_{\text {cond }}\right)$ & $19594 \mathrm{~Pa}$ & $n$ & 2
\end{tabular}




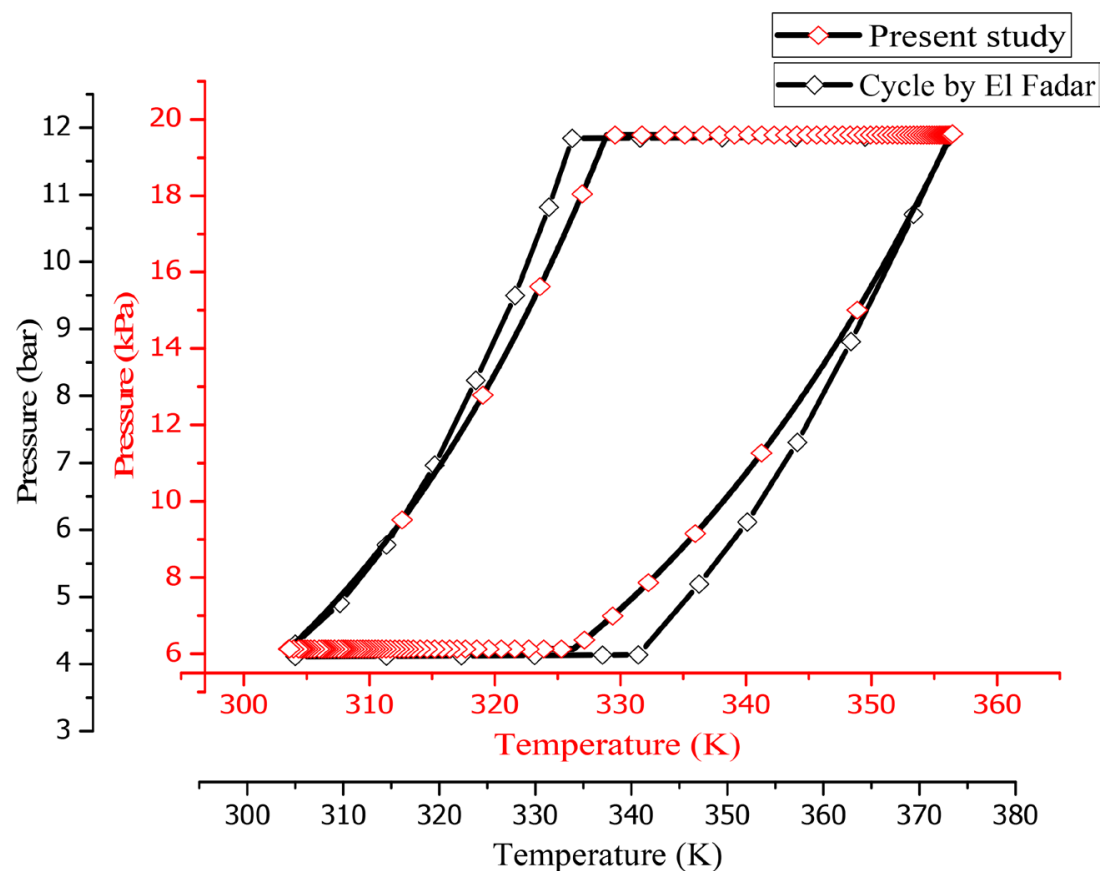

Figure 6. Model validation.

simulation conditions the simplifying assumptions mentioned and the numerical method used for resolution of equations or the physical parameters of the system components. In their study and quantitatively, the steam pressure of their system is higher because of the use of ammonia. This is perfectly normal because the vapor pressure of ammonia is greater than that of methanol. In view of this qualitative comparison, we can say that the numerical code we have developed allows to model an air conditioner by adsorption.

\subsection{Evolution of Cooling Unit Parameters}

The temperature, the pressure, and the adsorbed mass normally follow the evolution of the 4 phases of the cycle. They are undeniably linked and the evolution of their curves is also as shown in the figures. An increase of pressure accompanies the increase in temperature, and in the same way a decrease in the temperature leads to a decrease in the pressure. Overall, the temperature of the adsorbent influences all the other parameters of the system. Figure 7 shows the evolution of the temperatures of the cooling unit components while Figure 8 shows the evolution of the adsorbed mass. At first, heating is marked by a significant increase in the temperature of the zeolite that passes from the adsorption temperature $T_{a d s}=303.5 \mathrm{~K}$ to the temperature of desorption $T_{a 1}=328.8 \mathrm{~K}$, which depends on the pressure of the condenser. This significant increase is due largely to the heat supply by the hot geothermal fluid through the inner partition of the collector and by the closure of the connection between the condenser and the adsorber bed. As for the pressure inside the adsorber bed, it passes from the evaporation pressure $P_{e v}=6129 \mathrm{~Pa}$ at the pressure of condensation $P_{c d}=19,594$ $\mathrm{Pa}$. Concerning the quantity of the mass adsorbed, it is constant at its maximum 


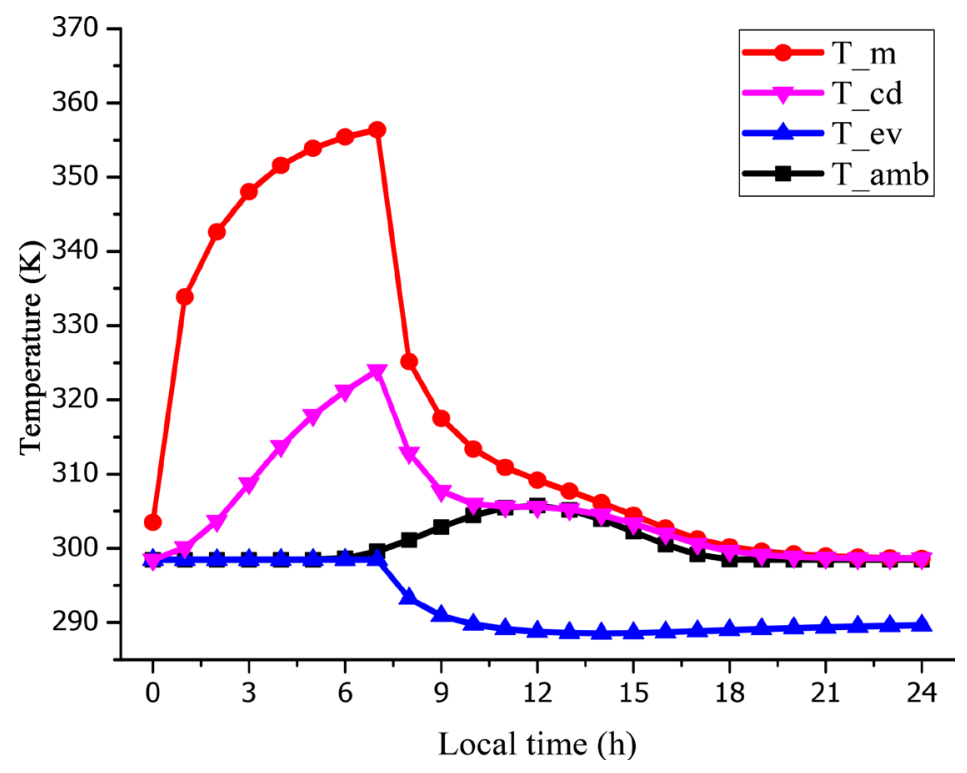

Figure 7. Temperatures evolution of the air conditioner components.

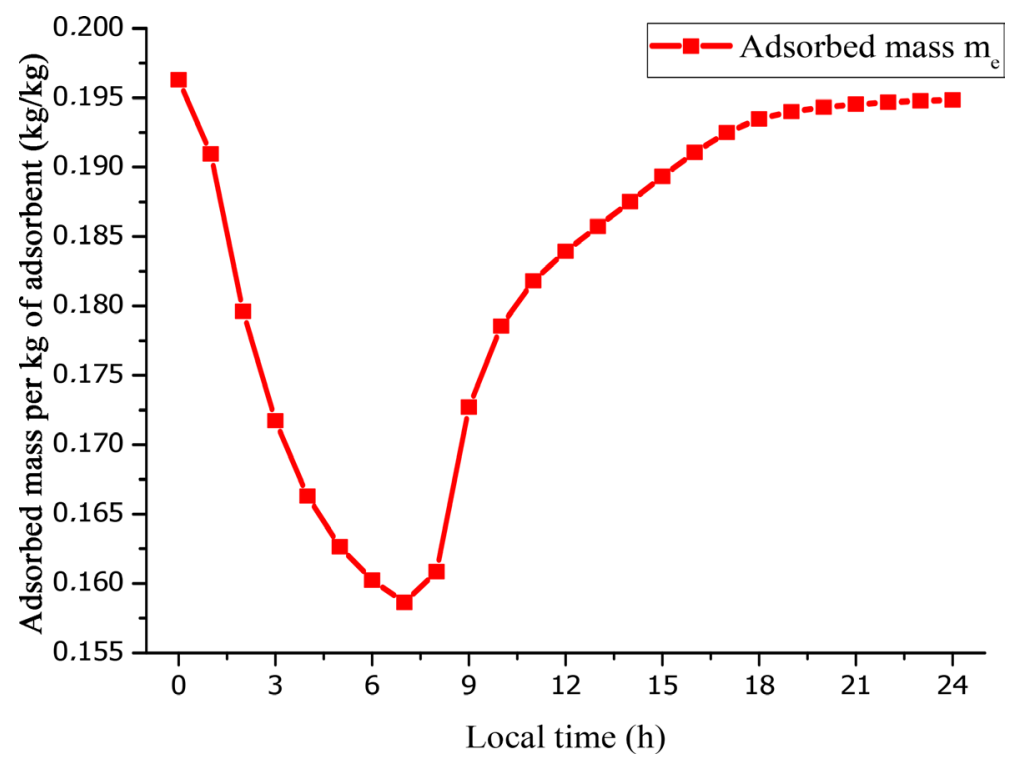

Figure 8. Evolution of the adsorbed mass.

value equaling to $0.196 \mathrm{~kg}$ of methanol by $\mathrm{kg}$ of zeolite.

Subsequently, when the pressure inside the sensor reaches that of the condenser, the system is in its $2^{\text {nd }}$ phase and this corresponds to the condensation of the desorbed methanol vapors of the adsorbent. This phase during which continuous heating is marked by the connection of the adsorber bed with the condenser allows the evacuation of methanol vapors. The bed temperature continues to increase up to the regeneration temperature $T_{g}=356.36 \mathrm{~K}$, but in a less significant manner this time. As for the pressure inside the captor, it remains equal to the pressure of the condenser. The condenser temperature is important during this phase. It increased from $298.4 \mathrm{~K}$ at the beginning of the condensation to $323.7 \mathrm{~K}$ at the end. The rejection of the heat amounts of the desorbed methanol vapors at 
the surface of the zeolite causes this increase in the condenser temperature. For the mass of the desorbed methanol vapor, it decreases as the zeolite is desorbed to reach a minimum value of $0.158 \mathrm{~kg}$ of methanol by $\mathrm{kg}$ of zeolite corresponding to the regeneration temperature.

When the zeolite reaches the regeneration temperature, the cooling starts. During this $3^{\text {rd }}$ phase, the link between the adsorber bed and the condenser along with the heating is cut. The cooling of the adsorbent bed is done by natural convection with the ambient temperature. The temperature of the zeolites then passes from $T_{g}$ to the intermediate temperature $T_{a 2}=326.25 \mathrm{~K}$. This cooling also leads to a decrease in the pressure inside the adsorber bed which will pass from the condensation pressure to the pressure of evaporation to promote low-pressure adsorption. During this time, the liquid methanol will come out of the condenser to enter the evaporator through the expansion valve to further undergo a pressure drop. During cooling, the amount of adsorbed mass remains at a minimum value.

Finally, the $4^{\text {th }}$ and last phase of the cycle corresponds to the adsorption during which the temperature continues to decrease due to the fixation of the methanol molecules in the zeolite by linking the evaporator with the adsorber bed. As for the pressure inside the adsorber bed, it remains constant to the evaporation pressure. The temperature of the evaporator is important during the evaporation-adsorption phase. It influences directly the time required for adsorption. It starts from $298.4 \mathrm{~K}$ and decreases considerably to reach a $283.9 \mathrm{~K}$ temperature. This temperature decrease is explained by the heat consumption stored in the evaporator and necessary for the adsorption of methanol vapor molecules in the zeolite. During adsorption, the amount of adsorbed mass increases to reach a maximum value of $0.194 \mathrm{~kg} / \mathrm{kg}$. Note that at the end of the adsorption-evaporation phase, methanol vapor cannot be totally desorbed and the total mass of adsorbed steam is less than the total mass of steam initially at the end of the adsorptionevaporation.

\subsection{Evolution of Habitat Temperatures}

Figure 9 shows the temperature of the indoor air of the habitat with and without a cooling unit. From $01 \mathrm{~h}$ to $08 \mathrm{~h}$, the curves of the two temperatures are superposed; this coincides with the three phases of the cooling unit except the evaporation and where the evaporator's temperature is equal to room temperature. From $8 \mathrm{~h}$ and with the evaporation of the quantities of methanol vapor in the evaporator, the temperature of the evaporator's wall begins to decrease. It is at this stage that everything is playing out precisely, the habitat air conditioning can actually begin, and the two curves separate. The habitat temperature with cooling unit has a small decrease before starting to rise in a very light way in the full period day. It reaches a $301.80 \mathrm{~K}$ peak at $14 \mathrm{~h}$ against a $304.19 \mathrm{~K}$ peak without the cooling unit. This makes a temperature difference of $\Delta t=2.39 \mathrm{~K}$ at $14 \mathrm{~h}$. This temperature decrease is explained by the thermal exchange between the habitat 
indoor air and the evaporator walls which are at low temperature. This shows that the evaporator produces a cooling effect within the habitat. The decrease in the habitat air temperature can continue significantly at the end of the day when the solar flux and the exterior ambient temperature decrease.

Figure 10 shows the profiles of the internal vertical walls of the living room with and without air conditioner. At the East and with the cooling unit, we observe a decrease in the wall temperature that reaches a $304.64 \mathrm{~K}$ peak at $13 \mathrm{~h}$ against $305.03 \mathrm{~K}$ at the same time without cooling unit. Just like with the East wall, we also see a decrease in the North wall with cooling unit. It reaches a $303.83 \mathrm{~K}$ peak at $14 \mathrm{~h}$ compared with $304.19 \mathrm{~K}$ without cooling unit. We observe

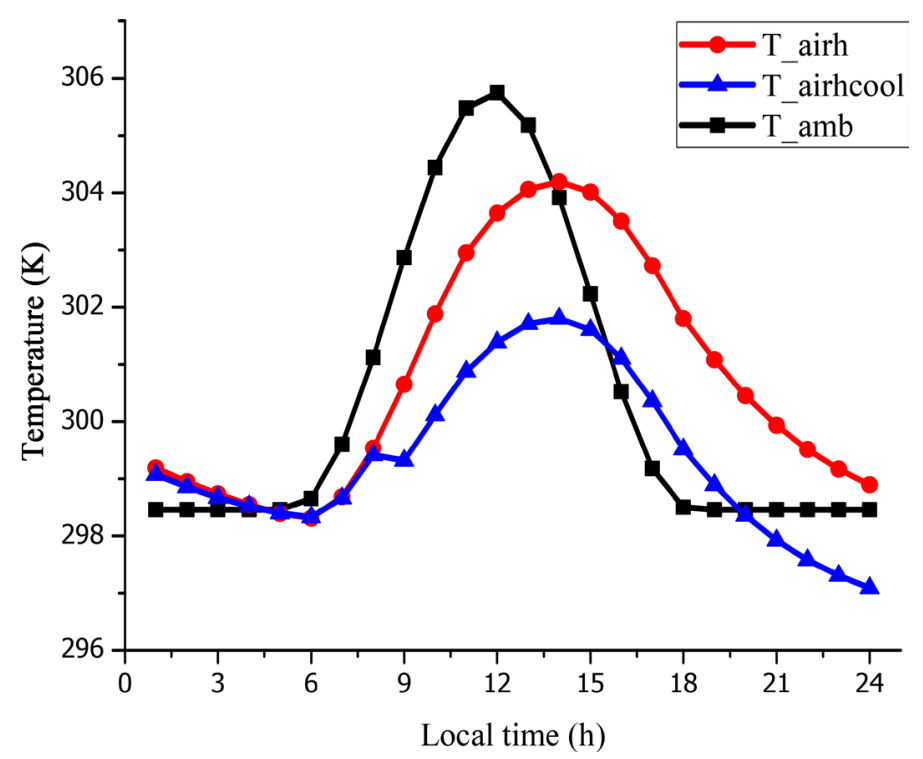

Figure 9. Temperature evolution of indoor air habitat with and without cooling unit.

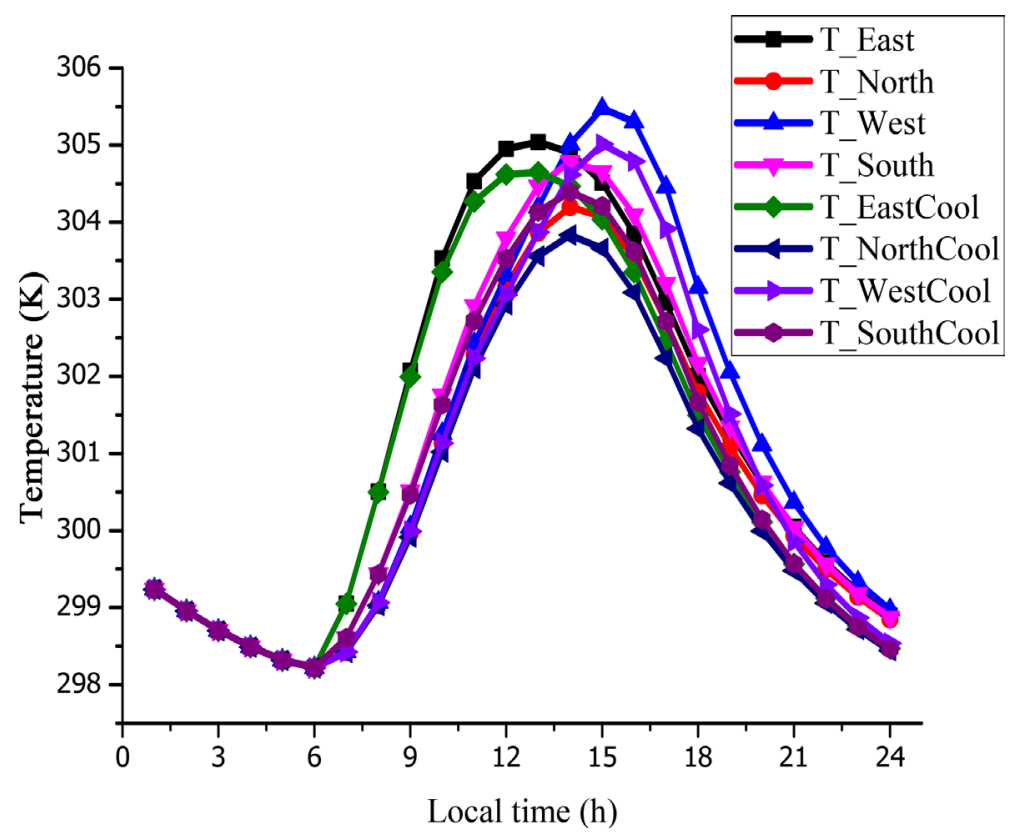

Figure 10. Temperature evolution of vertical walls with and without cooling unit. 
the same trends for West and South walls that respectively reach peaks of temperatures equal to $305.01 \mathrm{~K}$ at $15 \mathrm{~h}$ against $305.47 \mathrm{~K}$ without cooling unit and $304.39 \mathrm{~K}$ at $14 \mathrm{~h}$ against $304.78 \mathrm{~K}$ without cooling unit. This decrease can be explained by the diminution in the temperature of the internal air of the habitat under the effect of the air conditioner. This phenomenon causes a decrease by convection of the temperature of the interior walls. We observe the same trends for the ceiling and floor temperatures in Figure 11. At the first ceiling, the temperature with air conditioner evolves below the one without air conditioner. By cooling the habitat indoor air, the plafond temperature reaches $306.58 \mathrm{~K}$ peak at $13 \mathrm{~h}$ compared to $306.95 \mathrm{~K}$ without cooling unit. Just like at the indoor interior temperatures of the habitable enclosure, we observe a decrease in floor temperature with cooling unit. It reaches a $300.41 \mathrm{~K}$ peak at $16 \mathrm{~h}$, without cooling unit against $300.14 \mathrm{~K}$ at $15 \mathrm{~h}$ with cooling unit.

\subsection{Influence of Parameters on the Indoor air of Habitat}

Figure 12 shows the effect of the absorption coefficient of the walls. We find that the more the coefficient is the greater the indoor air temperature. It is the case with or without cooling unit. Without cooling unit and for a coefficient of absorption of the walls of 0.9 , we have a temperature peak of $306.74 \mathrm{~K}$ at $14 \mathrm{~h}$ For a coefficient of 0.1 , we have a $302.84 \mathrm{~K}$ peak at $14 \mathrm{~h}$. The increase in the wall absorption implies that a quantity of important flux arrives on the wall. This raises the temperature of the wall and therefore indoor air. We notice these same trends in the case of habitat with cooling unit but with lower temperature values. Thus, for 0.9 of the walls absorption coefficient, in a diurnal period, we have a $304.17 \mathrm{~K}$ peak at $14 \mathrm{~h}$ compared to $300.52 \mathrm{~K}$ at the same time for an absorption coefficient equal to 0.1 .

Figure 13 shows the effect of the thickness of the walls on the indoor air of

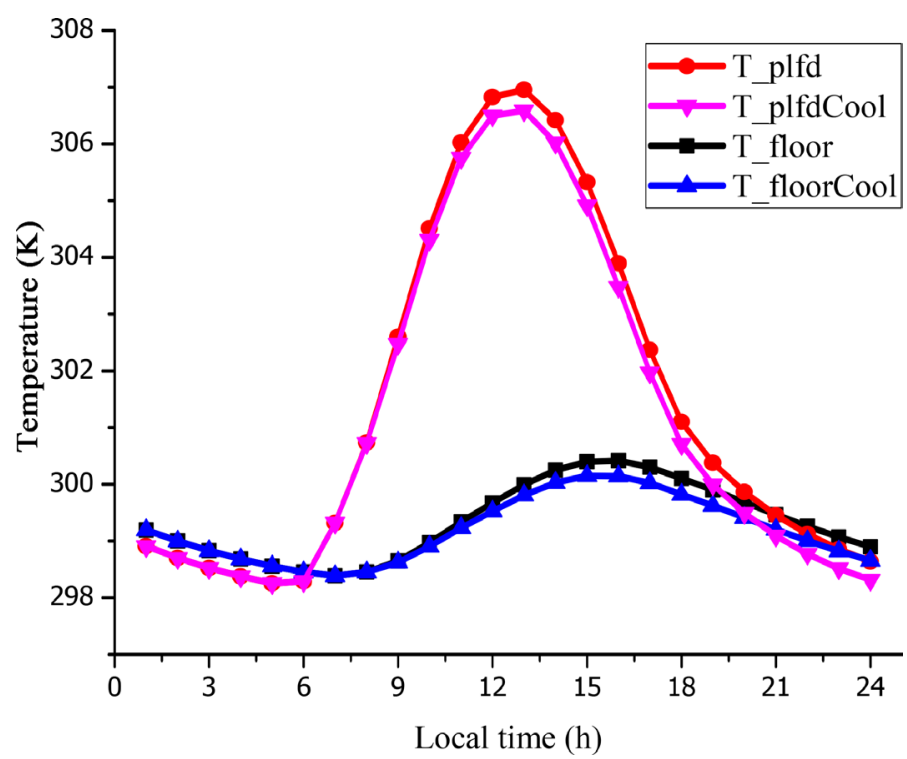

Figure 11. Temperature evolution of plafond and floor with and without cooling unit. 


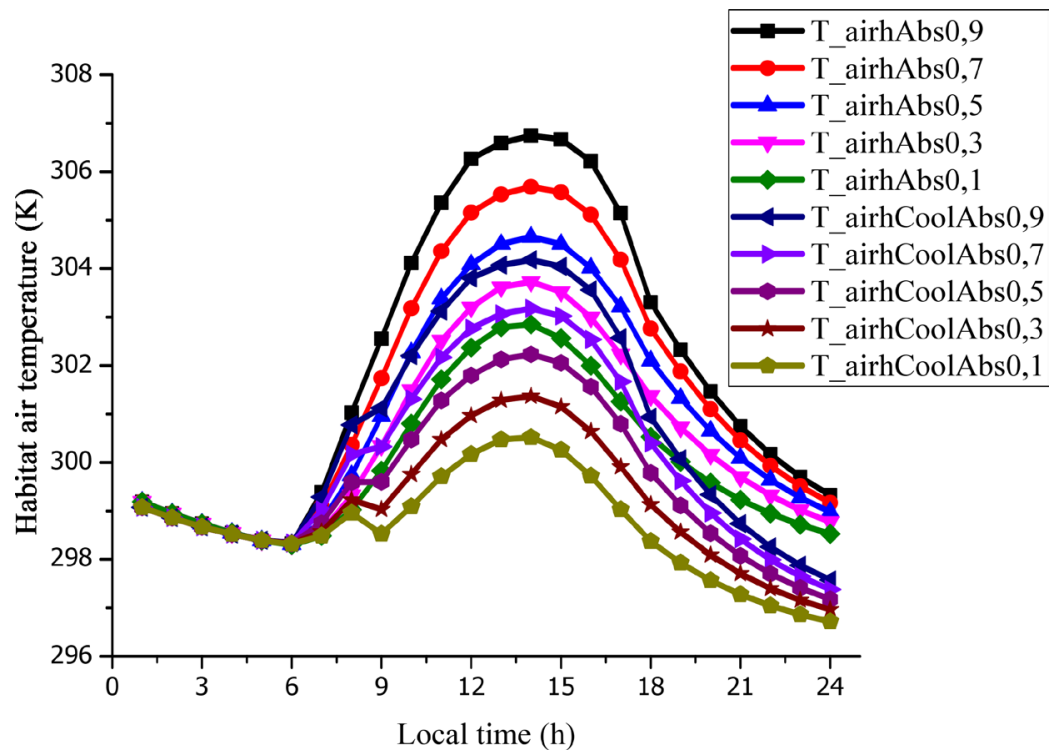

Figure 12. Effect of the walls absorption coefficient on the indoor air of habitat.

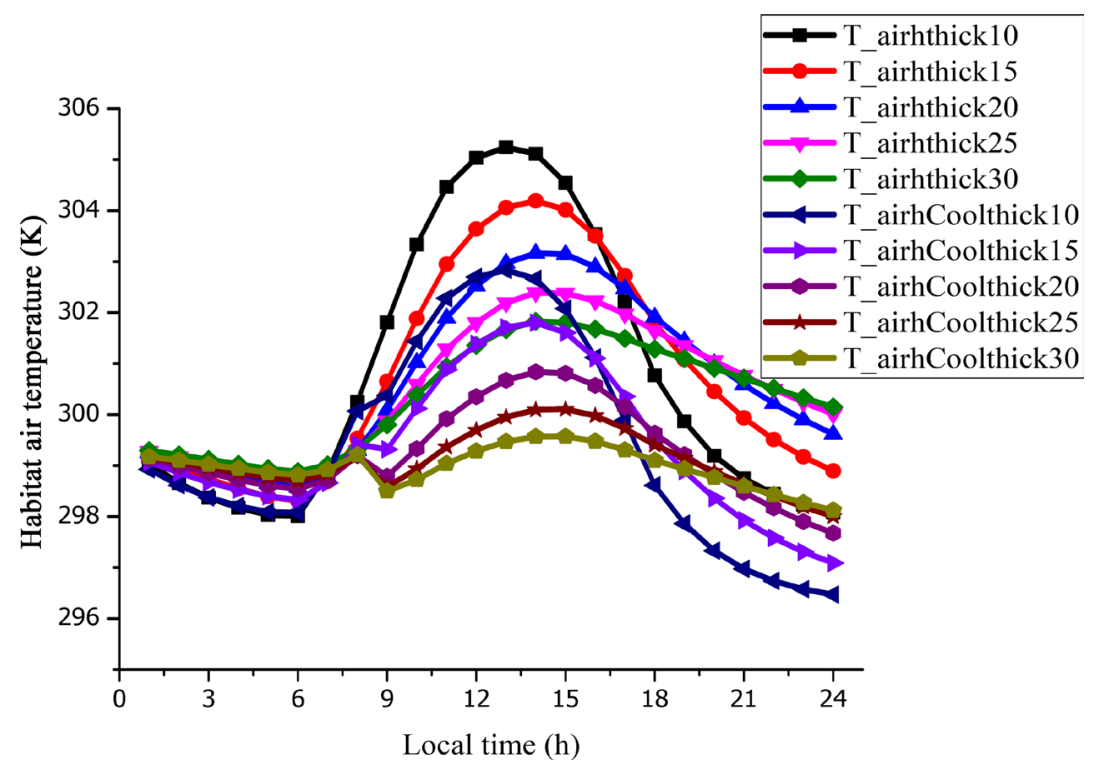

Figure 13. Effect of the walls thickness on the indoor air of habitat.

our habitat. It shows that when decreasing the thickness of the walls, the temperature of the habitat indoor air increases during the day period but decreases further during night. This shows that the decrease in the thickness of the walls increases the influence of the outer conditions on the temperature of the habitat indoor air. For a thickness of $10 \mathrm{~cm}$ and without cooling unit, we have a temperature peak of $305.24 \mathrm{~K}$ at $13 \mathrm{~h}$ while for a thickness of $30 \mathrm{~cm}$ we have a peak of temperature of $301.82 \mathrm{~K}$ at $14 \mathrm{~h}$. This gives a $3.39 \mathrm{~K}$ temperature difference for a shifting $1 \mathrm{~h}$ phase. One should note that the increase in the thickness of the walls implies less variations in the inner temperature of habitat and therefore less thermal losses. This is all the more valid for habitat with or without air conditioner. Moreover, with air conditioning, we observe the same trends with a tem- 
perature peak equal to $302.83 \mathrm{~K}$ at $12 \mathrm{~h}$ for a $10 \mathrm{~cm}$ wall thickness against a $299.56 \mathrm{~K}$ peak at $14 \mathrm{~h}$ for $30 \mathrm{~cm}$ of thickness.

Figure 14 shows the influence of the renewal rate of the habitat indoor air. To do this, we vary the renewal air rate with the ambient environment outside from 0.1 to 7 . The results show that the increase in the renewal rate of air leads to an increase in the internal temperature of habitat. For a renewal rate of 7 and without cooling unit, the habitat indoor air reaches a temperature peak equal to $304.73 \mathrm{~K}$ at $12 \mathrm{~h}$ against $304.19 \mathrm{~K}$ at $14 \mathrm{~h}$ when the renewal rate is 0.1 , a phase shift of 2 hours. The ambient outdoor temperature being more important than the habitat interior, the exchange by air renewal makes up the temperature of the habitat interior. We have the same observation in a habitat with cooling unit; the indoor air temperature rises and reaches $303.31 \mathrm{~K}$ when the air renewal rate is 7 at $12 \mathrm{~h}$ against $301.74 \mathrm{~K}$ at $14 \mathrm{~h}$ for a rate equal to 0.1 .

Figure 15 shows the influence of the solar flux on the temperature of the inner air of the habitat. For this, we have varied the overall global flux intensity from 400 to $1600 \mathrm{~W} / \mathrm{m}^{2}$. The results show that the flux has an impact on the interior living room, both for air-conditioned habitat and without cooling unit. An increase in the flux triggers grows in the indoor temperature of the habitable enclosure. For $1600 \mathrm{~W} / \mathrm{m}^{2}$ of maximum flux intensity at no room conditioning, we have a curve that evolves over those of others. It reaches a $305.92 \mathrm{~K}$ peak at $14 \mathrm{~h}$ against a $302.55 \mathrm{~K}$ peak at the same time for a maximum intensity flux equal to $400 \mathrm{~W} / \mathrm{m}^{2}$. The increase in the solar flux increases the exterior temperatures of the walls and the roof. The heat passes through the walls by conduction and warms up the interior of the habitat by convection. We observe the same trends for a habitat with air conditioner. For a maximum flux of $1600 \mathrm{~W} / \mathrm{m}^{2}$ of intensity, the indoor air temperature reaches a $303.33 \mathrm{~K}$ peak at $14 \mathrm{~h}$ against $300.33 \mathrm{~K}$ at the same time for a maximum flux of $400 \mathrm{~W} / \mathrm{m}^{2}$.

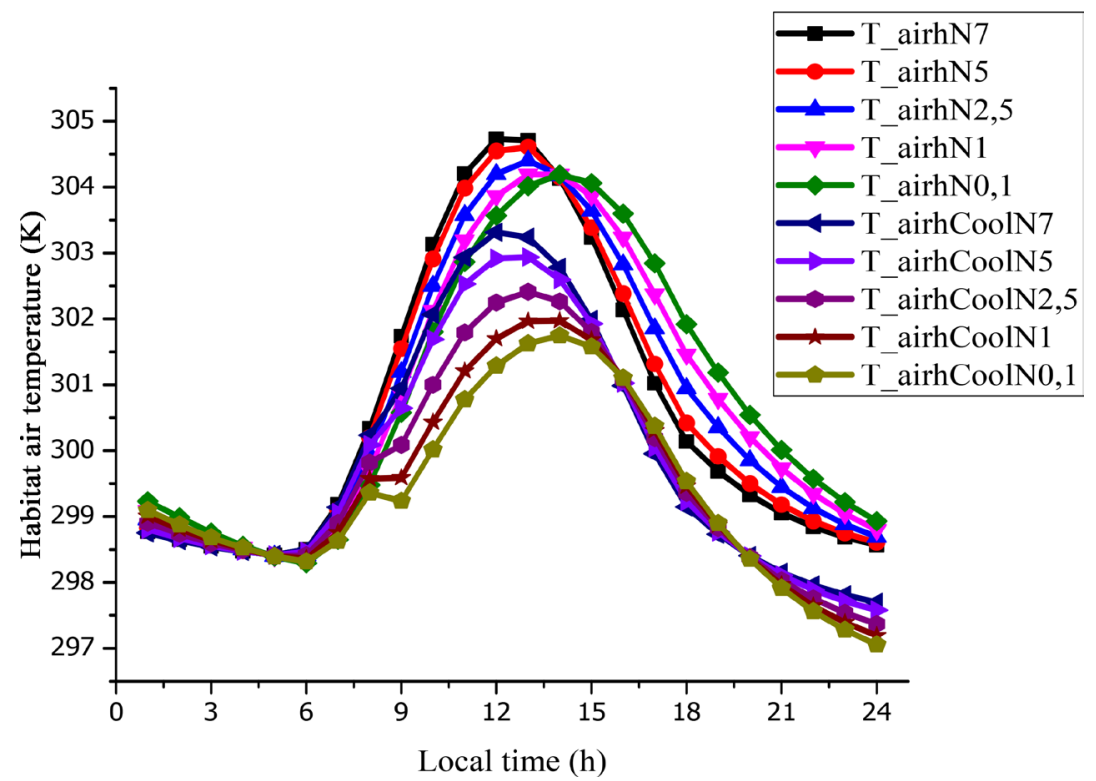

Figure 14. Influence of the renewal rate of the indoor air of habitat. 


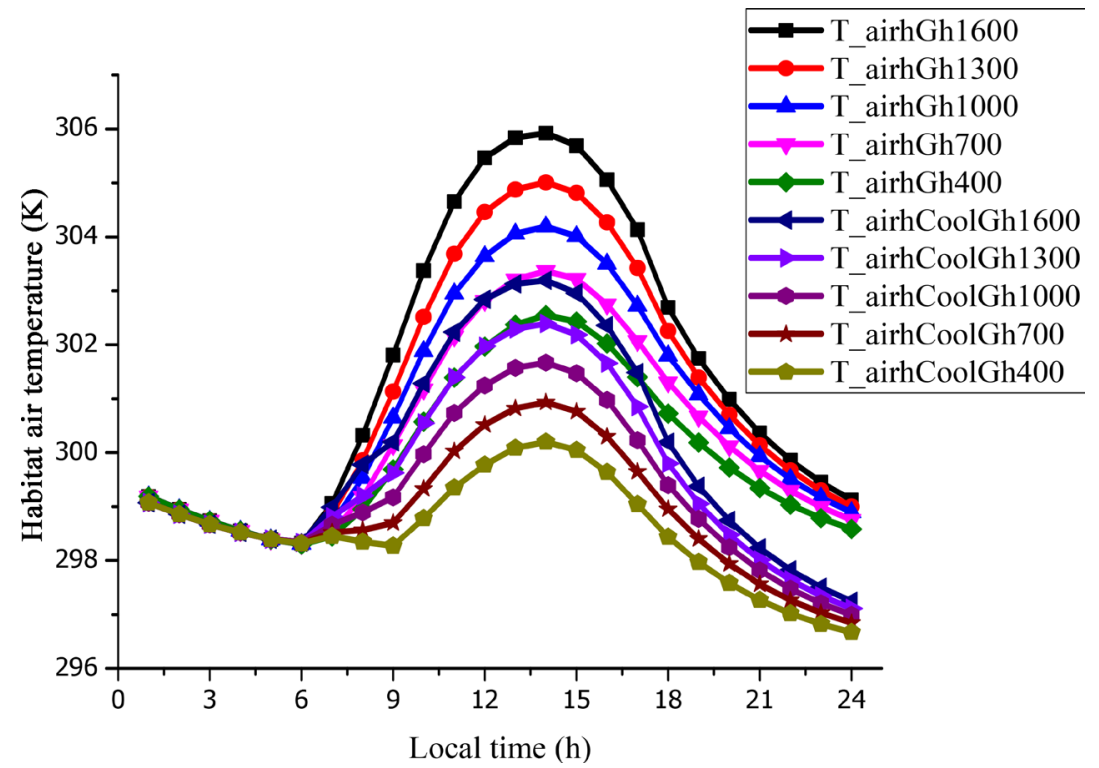

Figure 15. Influence of the solar flow on the indoor air of habitat.

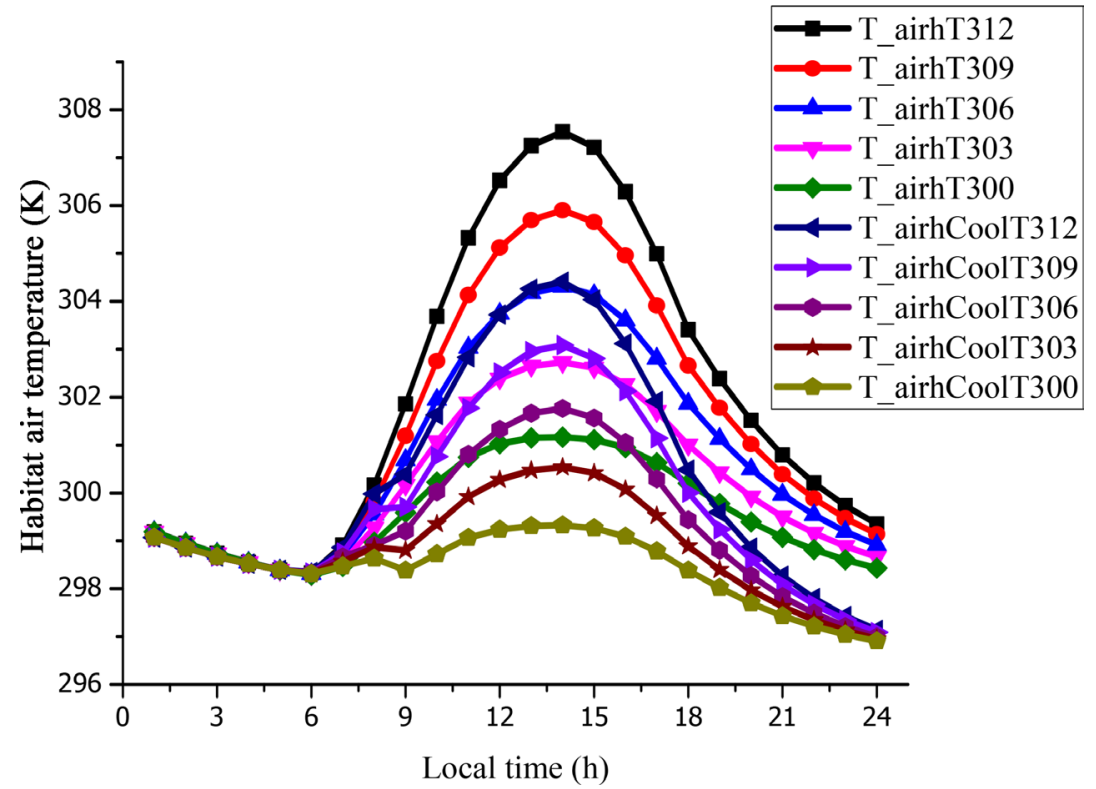

Figure 16. Influence of the ambient temperature on the indoor air of habitat.

Figure 16 shows the influence of the ambient temperature on the temperature of the inner air of the habitat. For this, we vary the maximum temperature from 300 to $312 \mathrm{~K}$. The results show that the maximum ambient temperature has a considerable impact on the inner temperature of the habitable enclosure. An increase in the maximum temperature of the ambience necessarily leads to an increase in the inner temperature of the habitable enclosure. This result is true for the habitat without cooling unit only for habitat with air conditioner. For a maximum temperature of $312 \mathrm{~K}$ in the habitat without cooling unit, we have a curve of the inner temperature evolving well above those of others. It reaches a 307.53 $\mathrm{K}$ peak at $14 \mathrm{~h}$ against a $301.16 \mathrm{~K}$ peak at the same time when the maximum tem- 
perature has a value of $300 \mathrm{~K}$. It is interesting to note that the difference between the maximum ambient temperature outside and the inner air of the living space increases with the increase in the maximum temperature.

This shows that for the maximum high temperature ambient temperature, the impact of the ambient temperature is more important than the flux. However, when the maximum ambient temperature is low, the influence of the flux is much greater; a trend that is confirmed through the roofs. We observe the same trends for a habitat with air conditioner. For a maximum room temperature of $312 \mathrm{~K}$, the inner air of the habitat reaches a temperature peak equal to $304.36 \mathrm{~K}$ at $14 \mathrm{~h}$ against a $299.31 \mathrm{~K}$ peak at the same time without cooling unit.

Figure 17 shows the influence of the convective exchange coefficient between the walls of the evaporator and the inner air of the habitat. For this, we set the exchange coefficient to a constant value by varying it from 1.5 to $6 \mathrm{~W} /\left(\mathrm{m}^{2} \cdot \mathrm{K}\right)$. For an exchange coefficient of $1.5 \mathrm{~W} /\left(\mathrm{m}^{2} \cdot \mathrm{K}\right)$, the inner air inhabitants reaches $301.72 \mathrm{~K}$ peak at $14 \mathrm{~h}$ against a $300.65 \mathrm{~K}$ peak at the same time for a heat exchange coefficient equal to $6 \mathrm{~W} /\left(\mathrm{m}^{2} \cdot \mathrm{K}\right)$. The increase in the coefficient of exchange results in a decrease of the temperature of the indoor air habitat and the decrease of the thermal exchange coefficient between the walls of the evaporator and the interior gives some that high temperature values. This is due to the fact that a high exchange coefficient implies a high exchange flow between the evaporator and the indoor air of habitat.

Figure 18 shows the influence of the exchange surface of the evaporator on the air of the habitat. For this, we vary the exchange surface from 1 to $5 \mathrm{~m}^{2}$. For a surface of $1 \mathrm{~m}^{2}$, the inner air of the habitat reaches a temperature peak equal to $303 \mathrm{~K}$ at $14 \mathrm{~h}$ against $301.08 \mathrm{~K}$ for an exchange surface equal to $5 \mathrm{~m}^{2}$. The increase in the exchange surface of the evaporator with the inner air of the habitat decreases the temperature of the indoor air. This is explained by the fact that a

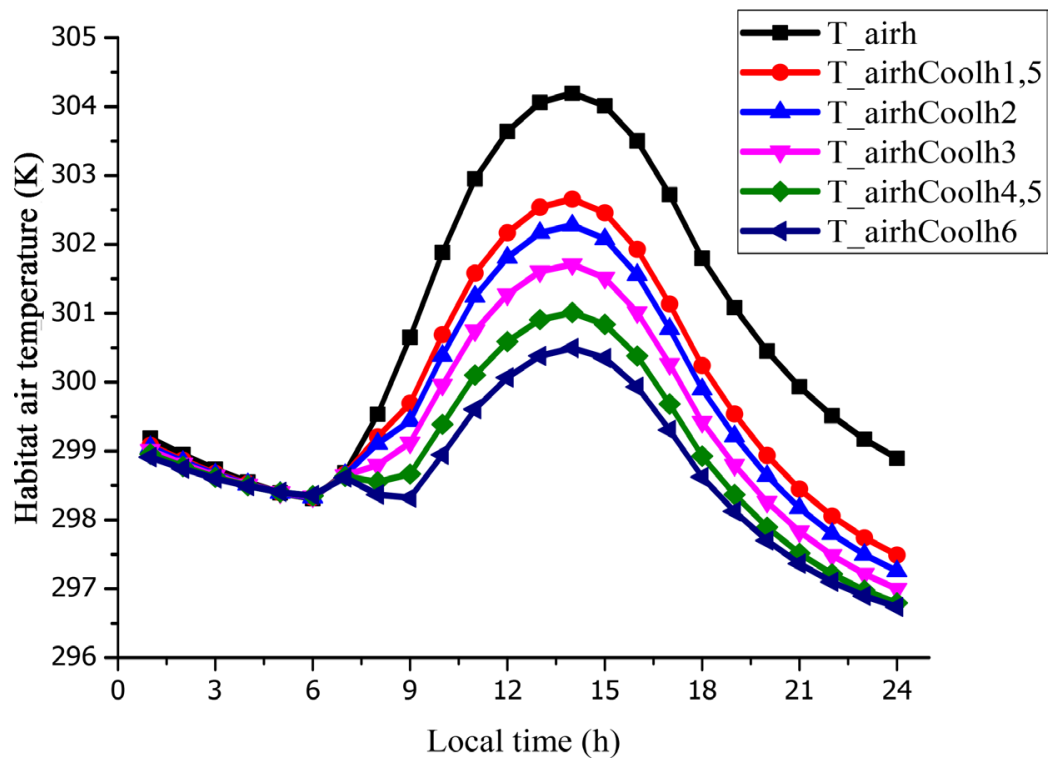

Figure 17. Influence of the convective exchange coefficient on the indoor air of habitat. 


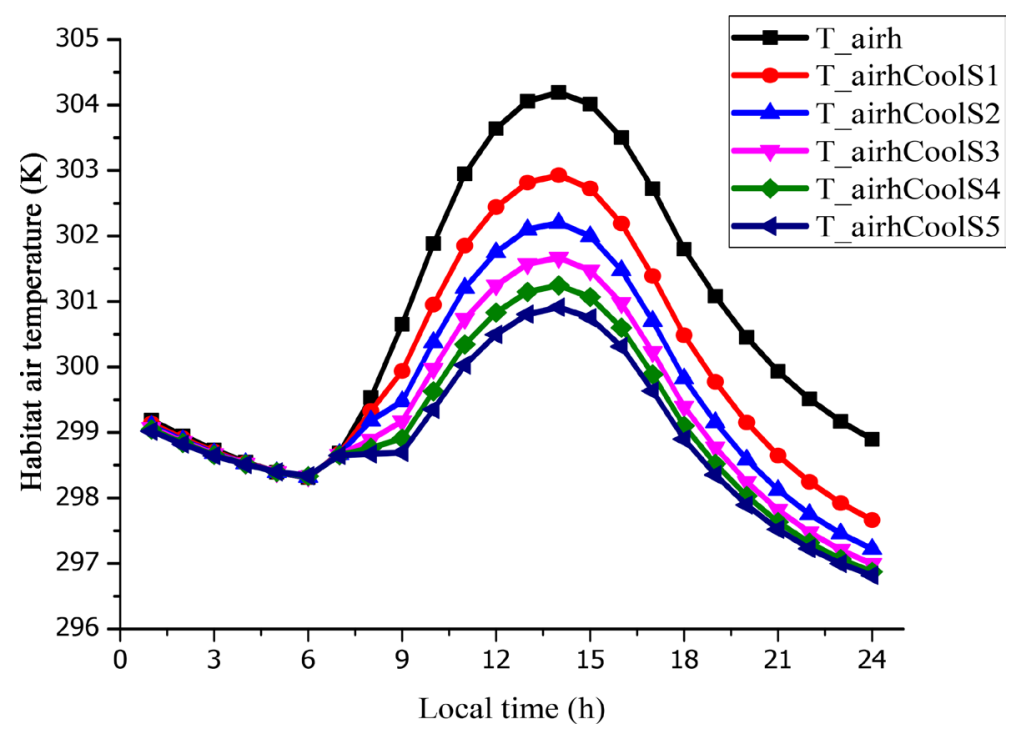

Figure 18. Influence of the evaporator exchange surface on the indoor air of habitat.

greater exchange surface of the evaporator involves larger exchanges between the evaporator and the inner air of habitat and therefore a significant decrease in the temperature of the latter.

\subsection{Study of Cooling Unit Performance}

In Table 3, we report the thermal performance of the air conditioner based on the temperature threshold system as follows $T_{\text {eva }}=280 \mathrm{~K}, T_{\text {ads }}=298 \mathrm{~K}, T_{\text {cond }}=$ $304 \mathrm{~K}$ and $T_{g}=363 \mathrm{~K}$. We find that the increase in evaporation temperature involves an increase in the $C O P_{t h}$ and the amount of cold product $Q_{e v}$. For an evaporation temperature from $270 \mathrm{~K}$ to $291 \mathrm{~K}$, we have respectively, a $C O P_{t h}$ which goes from 0.339 to 0.561 and a cold amount produces value from 247.05 to $405.96 \mathrm{~kJ} / \mathrm{kg}$. The increase in the evaporation temperature increases the saturation pressure in the evaporator and the maximum amount of the mass, which leads to an increase in cycling. An increase in the cycling mass implies a simultaneous increase in the amount of cold produced at the evaporator and the $C O P_{t h}$ of the air conditioning unit.

In addition, the increase in the adsorption temperature decreases the $C O P_{t h}$ and the amount of cold product. For this, $C O P_{t h}$ values vary respectively from 0.481 to 0.318 and cold product values from 351.51 to $209.95 \mathrm{~kJ} / \mathrm{kg}$. The increase in the adsorption temperature in the beginning of the cycle decreases the maximum amount of mass, which consequently reduces the cycling mass and therefore the performance of the machine. Then, by variating the condensation temperature from 295 to $317 \mathrm{~K}$, we respectively obtain a $C O P_{\text {th }}$ which goes from 0.592 to 0.213 and a quantity of cold product that varies from 424.03 to 160.74 $\mathrm{kJ} / \mathrm{kg}$. Thus, it appears that the increase in the condensation temperature reduces the performance of the system. This is explained by the fact that the increase in the condensation temperature increases the saturation pressure at the condenser, thus an increase in the temperature of desorption. However, the increase in the 
Table 3. Cooling unit performance.

\begin{tabular}{|c|c|c|c|}
\hline Component & Temperature (K) & $C O P_{t h}$ & $Q_{e v}(\mathrm{~kJ} / \mathrm{kg})$ \\
\hline \multirow{6}{*}{$T_{\text {eva }}$} & 270 & 0.339 & 247.04 \\
\hline & 273 & 0.380 & 276.76 \\
\hline & 278 & 0.441 & 321.46 \\
\hline & 283 & 0.495 & 359.58 \\
\hline & 288 & 0.539 & 390.72 \\
\hline & 291 & 0.561 & 405.96 \\
\hline \multirow[t]{6}{*}{$T_{a d s}$} & 280 & 0.481 & 384.18 \\
\hline & 285 & 0.488 & 380.48 \\
\hline & 290 & 0.486 & 369.49 \\
\hline & 300 & 0.454 & 326.93 \\
\hline & 310 & 0.381 & 259.94 \\
\hline & 316 & 0.318 & 209.95 \\
\hline \multirow[t]{6}{*}{$T_{\text {cond }}$} & 295 & 0.592 & 424.03 \\
\hline & 300 & 0.484 & 351.36 \\
\hline & 305 & 0.387 & 284.64 \\
\hline & 308 & 0.334 & 247.67 \\
\hline & 312 & 0.270 & 202.06 \\
\hline & 316 & 0.213 & 160.74 \\
\hline \multirow[t]{6}{*}{$T_{g}$} & 345 & 0.426 & 166.11 \\
\hline & 360 & 0.457 & 307.37 \\
\hline & 375 & 0.489 & 460.69 \\
\hline & 390 & 0.510 & 612.79 \\
\hline & 410 & 0.520 & 796.11 \\
\hline & 430 & 0.511 & 944.34 \\
\hline
\end{tabular}

temperature of desorption decreases the amount of mass and therefore the amount cycled. This leads to the decrease in the $C O P_{t h}$ and the amount of cold produced at the evaporator.

Finally, for a regeneration temperature from 345 to $430 \mathrm{~K}$, we have a $C O P_{\text {th }}$ that varies from 0.426 to 0.511 and a quantity of cold product that goes from 166.11 to $944.34 \mathrm{~kJ} / \mathrm{kg}$. We observe that an increase in the regeneration temperature increases the performance of the system. The increase in the regeneration temperature reduces the minimum mass and thus increases the cycling mass, which leads to better performance at the system level. Nevertheless, it is not necessary to have infinitely regeneration temperatures because it affects the physical abilities of certain materials that are limited to transmit a high range of heat as well. Added to this, the chemical and thermodynamic limits of adsorbent/adsorbate couples at high temperatures that are taken into account. That is why we observe 
that the $C O P_{\text {th }}$ reaches a maximum value than the amount of cold produced continues to increase in a monotone way.

\section{Conclusions}

In this study, we present a habitat model equipped with a cooling unit. The results show that the use of this cooling unit can help improve the internal atmosphere of buildings to give up some comfort to occupants. Thus:

- We have a temperature difference of $2.14 \mathrm{~K}$ on the indoor air of the habitat at $14 \mathrm{~h}$ if the air conditioning is started at $08 \mathrm{~h}$;

- Looking at the influence of physical parameters, we find that the absorption coefficient and the thickness of the walls as well as the exchanges by air renewal must be optimized if we want to keep a thermal comfort within the habitats;

- Although some input weather parameters such as the maximum flux and ambient temperature are heating the indoor air of the habitat, the use of cooling unit contributes to the decrease of its temperature;

- Regarding the level of the exchange between the inner air of habitat and the evaporator, it shows that a large surface of the evaporator as well as a high exchange coefficient can contribute to the decrease of the internal temperature of the habitat;

- The system can reach 0.46 of $C O P_{t h}$, if working with optimal temperatures.

- The cooling unit we developed in this work may be an alternative to the air conditioning system of buildings using the Geothermal Resource that the Comoros Islands benefit from. Ecologically, this system has interesting advantages but further work remains to be carried out such as conducting a dimensioning and an optimization of exchange surfaces between the evaporator and habitat.

\section{Acknowledgements}

The authors would like to thank the French Embassy (SCAC) to Comoros for the financial support.

\section{Conflicts of Interest}

The authors declare no conflicts of interest regarding the publication of this paper.

\section{References}

[1] Isaac, M. and van Vuuren, D.P. (2009) Modeling Global Residential Sector Energy Demand for Heating and Conditionning in the Context of Climate Change. Energy Policy, 37, 507-521. https://doi.org/10.1016/j.enpol.2008.09.051

[2] Saha, B.B., Akisawa, A. and Kashiwagi, T. (2001) Solar/Waste Heat Driven Two-Stage Adsorption Chiller: The Prototype. Renewable Energy, 23, 93-101. https://doi.org/10.1016/S0960-1481(00)00107-5

[3] Camara, Y., Chesneau, X. and Kante, C. (2018) Contribution to the Improvement of 
Thermal Comfort in a Bioclimatic Building by Integration of a Phase Change Material. International Journal of Engineering Research and science \& Technologie, 7, $1-24$.

[4] Do, J., Cha, D., Park, I., Kwon, O.K., Bae, J. and Park, J. (2019) Hydrothermal Synthesis and Application of Adsorbent Coating for Adsorption Chiller. Progress in Organic Coatings, 128, 59-68. https://doi.org/10.1016/j.porgcoat.2018.12.011

[5] Ilis, G.G. (2017) Influence of New Adsorbents with Isotherm Type V on Performance of an Adsorption Heat Pump. Energy, 119, 86-93. https://doi.org/10.1016/j.energy.2016.12.053

[6] Bonaccorsi, L., Calabrese, L., Freni, A. and Proverbio, E. (2013) Hydrothermal and Microwave Synthesis of SAPO (CHA) Zeolites on Aluminium Foams for Heat Pumping Applications. Microporous Mesoporous Materials, 167, 30-37. https://doi.org/10.1016/j.micromeso.2012.06.006

[7] Wittstadt, U., Fueldner, G., Andersen, O., Herrmann, R. and Schmidt, F. (2015) A New Adsorbent Composite Material Based on Metal Fiber Technology and Its Application in Adsorption Heat Exchangers. Energies, 8, 8431-8446.

https://doi.org/10.3390/en8088431

[8] Eun, T.-H., Song, H.-K., Han, J.H., Lee, K.-H. and Kim, J.-N. (2000) Enhancement of Heat and Mass Transfer in Silica-Expanded Graphite Composite Blocks for Adsorption Heat Pumps. Part II. Cooling System Using the Composite Blocks. International Journal of Refrigeration, 23, 74-81. https://doi.org/10.1016/S0140-7007(99)00036-5

[9] Rocky, K.A., Islam, M.A., Pal, A., Ghosh, S., Thu Nasruddin, K. and Saha, B.B. (2020) Experimental Investigation of the Specific Heat Capacity of Parent Materials and Composite Adsorbents for Adsorption Heat Pumps. Applied Thermal Engineering, 164, Article ID: 114431.

[10] Seol, S.-H., Nagano, K. and Togawa, J. (2020) Modeling of Adsorption Heat Pump System Based on Experimental Estimation of Heat and Mass Transfer Coefficients. Applied Thermal Engineering, 171, Article ID: 115089.

[11] Dawoud, B. (2013) Water Vaporadsorption Kinetics on Small and Full Scale Zeolite Coated Adsorbers: A Comparison. Applied Thermal Engineering, 50, 1645-1651.

[12] Wittstadt, U., Füldner, G., Laurenz, E., Warlo, A., Große, A., Herrmann, R., Schnabel, L. and Mittelbach, W. (2017) A Novel Adsorption Module with Fiber Heat Exchangers: Performance Nalysis Based on Driving Temperature Differences. Renew Energy, 110, 154-161. https://doi.org/10.1016/j.renene.2016.08.061

[13] Ammann, J., Michel, B., Studart, A. and Ruch, P. (2019) Sorption Rate Enhancement in SAPO-34 Zeolite by Directed Mass Transfer Channels. International Journal of Heat and Mass Transfer, 130, 25-32.

https://doi.org/10.1016/j.ijheatmasstransfer.2018.10.065

[14] Pahinkar, D.G., Boman, D.B. and Garimella, S. (2020) High Performance Microchannel Adsorption Heat Pumps. International Journal of Refrigeration, 19, 184-194.

[15] Shi, Z., Liang, H., Yang, W., Liu, J., Liu, Z. and Qiao, Z. (2020) Machine Learning and in Silico Discovery of Metal-Organic Frameworks: Methanol as a Working Fluid in Adsorption-Driven Heat Pumps and Chillers. Chemical Engineering Science, 214, Article ID: 115430. https://doi.org/10.1016/j.ces.2019.115430

[16] Karmakar, A., Prabakaran, V., Zhaoa, D. and Chua, K.J. (2020) A Review of MetalOrganic Frameworks (MOFs) as Energy-Efficient Desiccants for Adsorption Driven Heat-Transformation Applications. Applied Energy, 269, Article ID: 115070. https://doi.org/10.1016/j.apenergy.2020.115070 
[17] Al-Dadah, R., Mahmoud, S., Elsayed, E., Youssef, P. and Al-Mousawi, F. (2020) Metal-Organic Framework Materials for Adsorption Heat Pumps. Energy, 190, Article ID: 116356. https://doi.org/10.1016/j.energy.2019.116356

[18] Passos, E., Meunier, F. and Gianola, J.C. (1986) Thermodynamic Performance Improvement of an Intermittent Solar-Powered Refrigeration Cycle Using Adsorption of Methanol on Activated Carbon. Heat Recovery System, 6, 259-264. https://doi.org/10.1016/0198-7593(86)90010-X

[19] Critoph, R.E. (1988) Performance Limitations of Adsorption Cycles for Solar Cooling. Solar Energy, 41, 21-31.

[20] Zheng, W., Worek, W. and Nowakowski, G. (1995) Effect of Design and Operating Parameters on the Performance of Two-Bed Sorption Heat Pump Systems. Journal of Energy Resources Technology, 117, 67-74. https://doi.org/10.1115/1.2835323

[21] Meunier, F. (1993) Thermal Swing Adsorption Refrigeration (Heat Pump). Separations Technology 3, 143-150.

[22] Schicktanz, M., Hugenell, P. and Henninger, S.K. (2012) Evaluation of Methanol/Activated Carbon for Thermally Driven Chillers, Part II: The Energy Balance Model. International Journal of Refrigeration, 35, 554-561.

https://doi.org/10.1016/j.ijrefrig.2011.03.014

[23] Sward, B.K., LeVan, M.D. and Meunier, F. (2000) Adsorption Heat Pump Modeling: The Thermal Wave Process with Local Equilibrium. Applied Thermal Engineering, 20, 759-780. https://doi.org/10.1016/S1359-4311(99)00051-4

[24] Tubreoumya, G.C., Dissa, A.O., Tiendrebeogo, E.S., Chesneau, X., Compaoré, A., Haro, K., Konseibo, C.D., Zeghmati, B. and Koulidiati, J. (2017) Contribution to the Modeling of a Solar Adsorption Refrigerator under the Climatic Conditions of Burkina Faso. Energy and Power Engineering, 9, 119-135.

https://doi.org/10.4236/epe.2017.92010

[25] Chekirou, W., Chikouche, A., Boukheit, N., Karaali, A. and Phalippou, S. (2014) Dynamic Modelling and Simulation of the Tubular Adsorber of a Solid Adsorption Machine Powered by Solar Energy. International Journal of Refrigeration, 39, 137-151. https://doi.org/10.1016/j.ijrefrig.2013.11.019

[26] Bogie, I. and Charroy, J. (2015) Comoros Surface Exploration, Geophysics and Summation. Jacobs, Auckland.

[27] Bachèlery, P. and Coudray, P. (1993) Carte volcano-tectonique de la Grande Comore (Njazidja) au 1/50000 avec notice explicative. Ed. Mission Française de cooperation aux Comores, Saint-Denis de La Réunion.

[28] Savin, C., Ritz, M., Join, J.-L. and Bachelery, P. (2001) Hydrothermal System Mapped by CSAMT on Karthala Volcano, Grande Comore Island, Indian Ocean. Journal of Applied Geophysics, 48, 143-152. https://doi.org/10.1016/S0926-9851(01)00078-7

[29] Muchemi, G.G., Onacha, S.A. and Wambugu, J. (2008) Reconnaissance and Inception Report for Geothermal Resources Exploration Program of the Grande Comore. Internal KenGen Report for the Federal Government of Comoros, Unpublished.

[30] McAdams, W.H. (1964) Transmission de la chaleur. Dunod, Paris.

[31] Seghir-Ouali, S., Saury, D., Harmand, S., Phillipart, O. and Laloy, D. (2006) Convective Heat Transfer Inside a Rotating Cylinder with an Axial Air Flow. International Journal of Thermal Sciences, 45, 1166-1178. https://doi.org/10.1016/j.ijthermalsci.2006.01.017

[32] Churchill, S.W. and Chu, H.H.S. (1975) Correlating Equations for Laminar and Tur- 
bulent Free Convection from a Vertical Plate. International Journal of Heat and Mass Transfer, 18, 1323-1329. https://doi.org/10.1016/0017-9310(75)90243-4

[33] Duffie, J.A. and Beckman, W.A. (2013) Solar Engineering of Thermal Processes. 4th Edition, John Wiley \& Sons, Hoboken.

[34] Ushiki, I., Sato, Y., Ota, M. and Inomata, H. (2016) Adsorption Equilibria of Volatile Organic Compounds on Various Adsorbents in Supercritical Carbon Dioxide: Measurement and Analysis by the Dubinin-Astakhov Equation. Fluid Phase Equilibria, 450, 58-67. https://doi.org/10.1016/j.fluid.2016.02.007

[35] Saleh, M.M., Al-Dadah, R., Mahmoud, S., Elsayed, E. and El-Samni, O. (2020) Wire Fin Heat Exchanger Using Aluminium Fumarate for Adsorption Heat Pumps. Applied Thermal Engineering, 164, Article ID: 114426.

https://doi.org/10.1016/j.applthermaleng.2019.114426

[36] Fadar, A.E., Mimet, A. and Pérez-Garcia, M. (2009) Modelling and Performance Study of a Continuous Adsorption Refrigeration System Driven by Parabolic Trough Solar Collector. Solar Energy, 83, 850-861.

https://doi.org/10.1016/j.solener.2008.12.003 


\section{Nomenclature}

\section{Mains letters}

c Volume heat of air $\left(\mathrm{J} \cdot \mathrm{m}^{-3} \cdot \mathrm{K}^{-1}\right)$

$C$ Spécifique heat $(\mathrm{J} / \mathrm{Kg} / \mathrm{K})$

$D$ Dubinin-Astakhov parameter

$D_{m} \quad$ Diameter (m)

$E \quad$ Activation energy (J)

$e_{p}$ Thickness (m)

$F \quad$ Form factor

$G \quad$ Global solar flux $\left(\mathrm{W} / \mathrm{m}^{2}\right)$

$h$ Thermal transfer coefficient $\mathrm{W} /\left(\mathrm{m}^{2} \cdot \mathrm{K}\right)$

$I$ Incident solar flux $\left(\mathrm{W} / \mathrm{m}^{2}\right)$

$k \quad$ Mass transfer coefficient

$L \quad$ Latent heat $(\mathrm{J} / \mathrm{kg})$

$L \quad$ Characteristic length (m)

$M \quad$ Mass (kg)

$m$ Adsorbate concentration/kg of adsorbent

$N \quad$ Air renewal rate $\left(\mathrm{h}^{-1}\right)$

$n \quad$ Dubinin-Astakhov parameter

$P$ Pressure $(\mathrm{Pa})$

$Q \quad$ Quantity of cold product (J)

$Q_{\text {tota }}$ Heat provides adsorber (J)

$R \quad$ Characteristic constant of gas

$R_{a} \quad$ Rayleigh number

$S$ Surface $\left(\mathrm{m}^{2}\right)$

$T$ Temperature (K)

$t$ Time (s)

$U$ Flow velocity $(\mathrm{m} / \mathrm{s})$

$V \quad$ Wind velocity $(\mathrm{m} / \mathrm{s})$

$V_{o l}$ Volume $\left(\mathrm{m}^{3}\right)$

$W$ Adsorption capacity $\left(\mathrm{m}^{3}\right)$

$\Delta H$ Isosteric heat of adsorption $(\mathrm{J} / \mathrm{kg})$

$\Delta x$ Section $(\mathrm{m})$

$\Delta m$ Mass cycled $(\mathrm{kg} / \mathrm{kg})$

\section{Greek Letters}

$a$ Coefficient of absorption

$\varepsilon \quad$ Adsorption potential

$\lambda$ Thermal conductivity $\mathrm{W} /(\mathrm{m} \cdot \mathrm{K})$

$\begin{array}{ll}\sigma & \text { Constant of Boltzmann } \\ \rho & \text { Density }\left(\mathrm{kg} / \mathrm{m}^{3}\right) \\ \phi & \text { Exchange by renewal air } \\ \varphi & \text { Flux density }\end{array}$

Exponents

$\begin{array}{ll}\text { ads } & \text { Adsorption } \\ \mathrm{c} & \text { Conduction } \\ \mathrm{cv} & \text { Convection } \\ \mathrm{des} & \text { Desorption } \\ \mathrm{r} & \text { Radiation } \\ \mathrm{x} & \text { Transfer mode }\end{array}$

Index

air Air

airh Habitat air

amb Ambient

$\mathrm{cw} \quad$ Cooling unit wall

cwo External wall of cooling unit

cwi Internal wall of cooling unit

cd Condenser

cond Condensation

e Methanol

ev Evaporator

eva Evaporation

f Fluid

g Regeneration

h Habitat wall

hex External wall of habitat

hin Internal wall of habitat

m Mixture zeolite/methanol

max Maximum

min Minimum

$\mathrm{p} \quad$ inner small wall

pi Inner face of small wall

pe Outer face of small wall

sky Sky

soil Soil

z Zeolite 